Portland State University

PDXScholar

\title{
An Assessment of the Transmission Electron Microscope for the Study of Aerosol-Gas Interactions: Direct Observations of Sodium Chloride Hydration Phenomena
}

Antony David Clarke

Portland State University

Follow this and additional works at: https://pdxscholar.library.pdx.edu/open_access_etds

Part of the Physics Commons

Let us know how access to this document benefits you.

\section{Recommended Citation}

Clarke, Antony David, "An Assessment of the Transmission Electron Microscope for the Study of AerosolGas Interactions: Direct Observations of Sodium Chloride Hydration Phenomena" (1978). Dissertations and Theses. Paper 2850.

https://doi.org/10.15760/etd.2844

This Thesis is brought to you for free and open access. It has been accepted for inclusion in Dissertations and Theses by an authorized administrator of PDXScholar. Please contact us if we can make this document more accessible: pdxscholar@pdx.edu. 
AN ABSTRACT OF THE THESIS OF Antony clarke for the Master of Science in Physics presented August 1, 1978.

Title: An Assessment of the Transmission Electron Microscope for the Study of Aeroso1-Gas Interactions: Direct Observations of Sodium Chloride Hydration Phenomena.

APPROVED BY MEMBERS OF THE THESIS COMMTTEE:
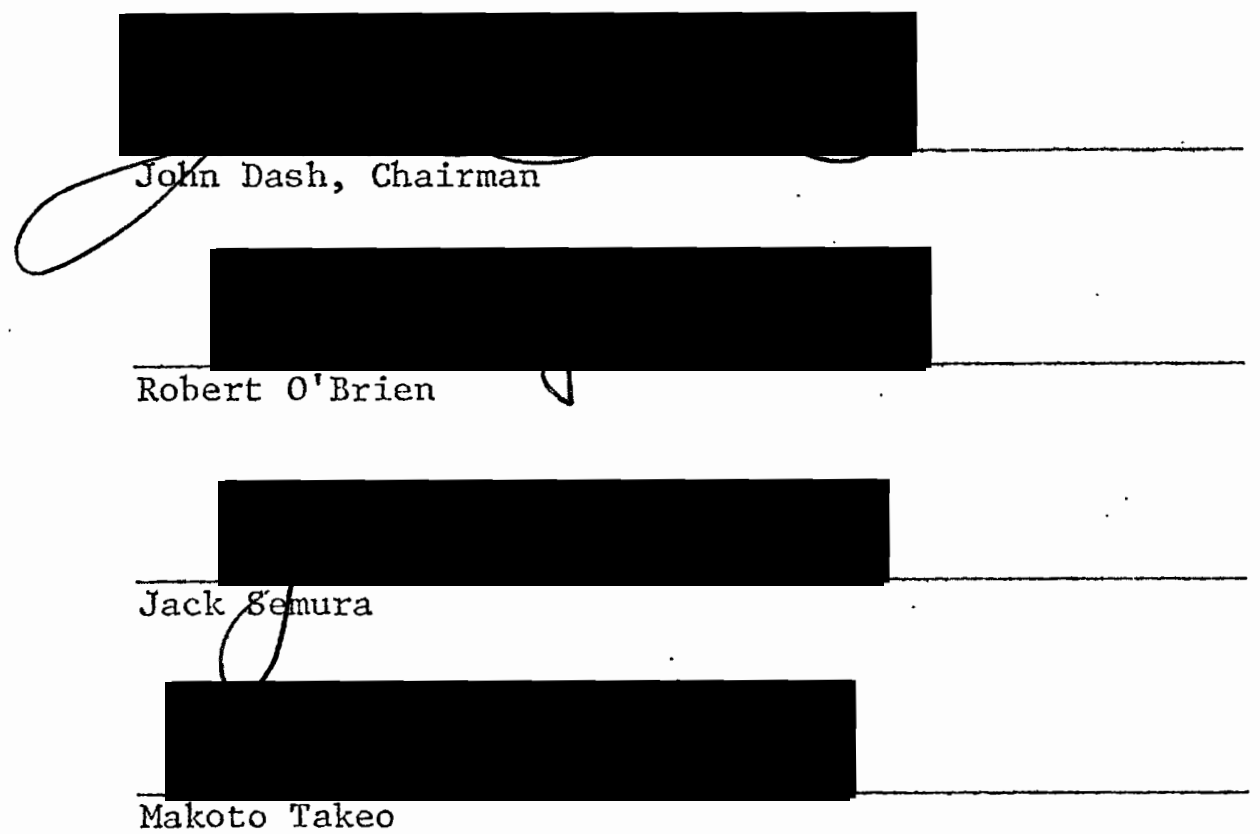

An experimental study of solid-gas interactions was made for sodium chloride particles, using a specially fabricated environmental chamber in a transmission electron microscope. It was found that under suitable conditions the hydration and dehydration of these particles could be directly observed and quantitatively measured. Measurements of growth were obtained with a time resolution of one-thirtieth of a 
second for particles having diameters ranging from $0.02 \mu \mathrm{m}$ to $1.0 \mu \mathrm{m}$. Qualitative and quantitative measurements indicated reasonable agreement with less direct measurements in the literature. The hysteresis effect for completely dissolved particles was observed, and measurements support the theory that the energetics of formation of critical nuclei of $\mathrm{NaCl}$ in the liquid phase is responsible for the effect. Growth measurements for particles in the $0.02 \mu \mathrm{m}$ to $0.2 \mu \mathrm{m}$ range were also made. These indicate that both the Kelvin and curvature-solubility effects are being observed.

Limitations, shortcomings, and potential improvements of the method are also considered. 
AN ASSESSMENT OF THE TRANSMISSION ELECTRON MICTOSCOPE FOR THE STUDY OF AEROSOL-GAS INTERACTIONS:

DIRECT OBSERVATIONS OF SODIUM CHLORIDE HYDRATION PHENOMENA

$$
\text { by }
$$

ANTONY DAVID CLARKE

A thesis submitted in partial fulfillment of the requirements for the degree of

MASTER OF SCIENCE

in

PHYS ICS 
TO THE OFFICE OF GRADUATE STUDIES AND RESEARCH:

The members of the Committee approve the thesis of Antony David Clarke presented August 1, 1978.
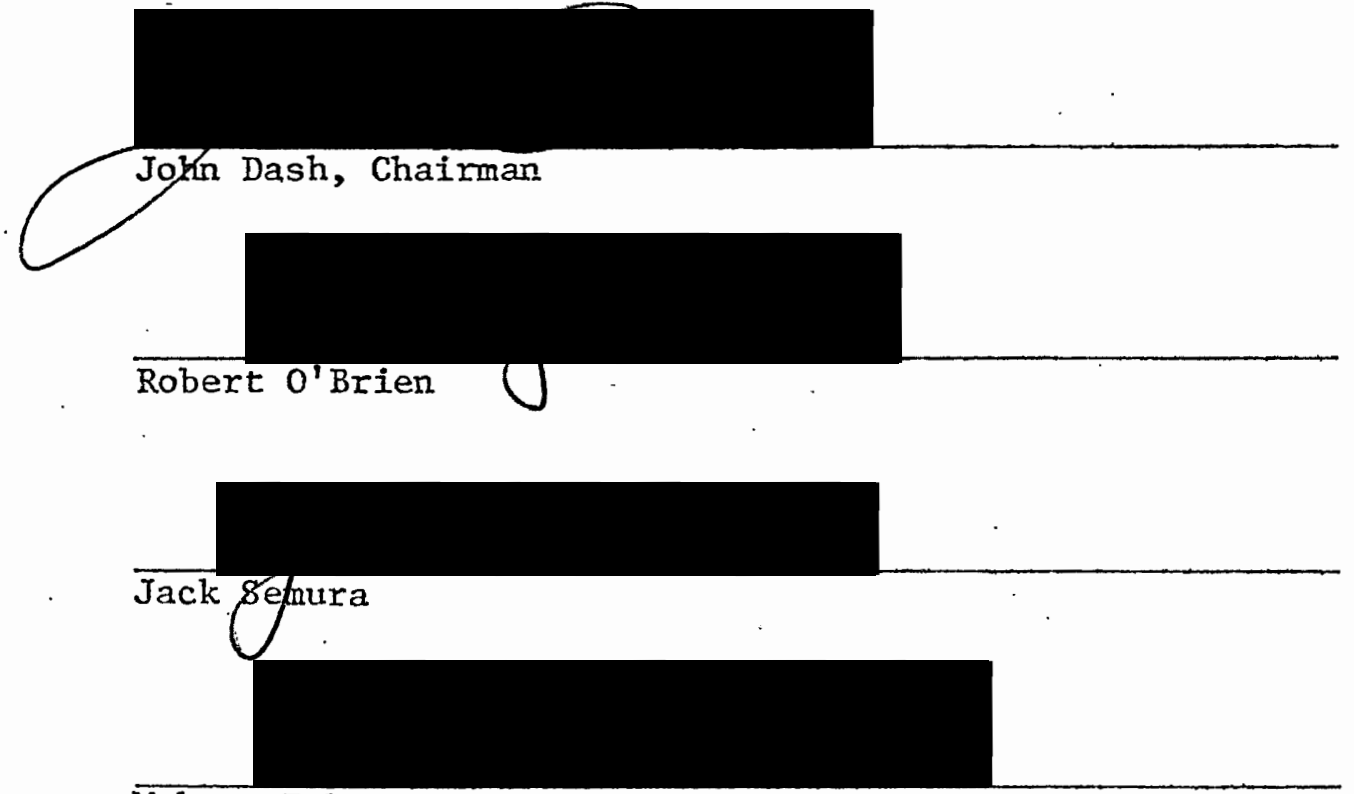

Makoto Takeo

APPROVED:

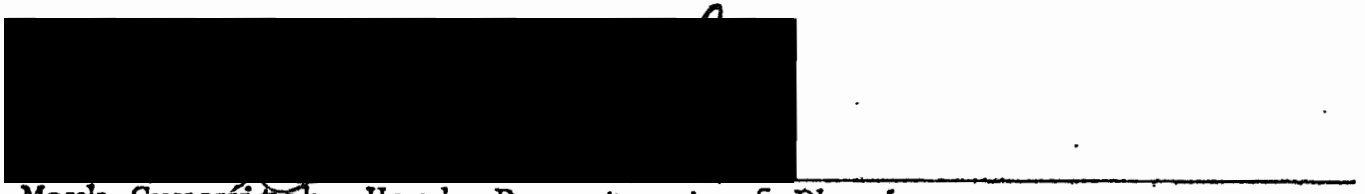

Mark Gurevitch, Head, Department of Physics

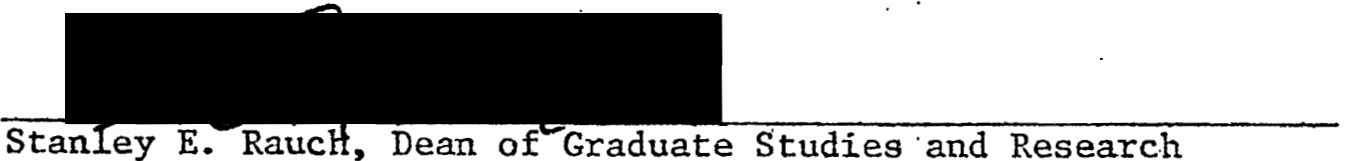




\section{ACKNOWLEDGEMENTS}

The author would like to thank his advisor Dr. John Dash for his continued support and encouragement during this work and for all his efforts on my behalf. Appreciation is also extended to Dr. Robert $0^{\prime}$ Brien for numerous discussions and assistance.

Special thanks are also due to Pat Green for his cheerful response to numerous equipment modification requests and to $H$. M. Nagarathna for valuable help in data collection and processing. Appreciation is also extended to Dr. Tom Chung, whose original efforts and preliminary collaboration made this work possible.

I am also grateful for the personal support, understanding, and patience of my wife Joan during the completion of this work. 
TABLE OF CONTENTS

PAGE

ACKNOWLEDGEMENTS

LIST OF TABLES

$\mathbf{v}$

LIST OF FIGURES

vi

SECTION

I INTRODUCTION . . . . . . . . . . . . . . .

II EXPERIMENTAL . . . . . . . . . . . . . . .

Experimental Situation .............

Experimental Procedure . . . . . . . . .

Sample Collection . . . . . . . . . . . .

III EXPERIMENTAL RESULTS . . . . . . . . . . . . . 17

IV THEORETICAL PRELIMINARY . . . . . . . . . . . 37

$\checkmark \quad$ INTERPRETATION OF RESULTS . . . . . . . . . . . 43

VI CONCLUSION . . . . . . . . . . . . . . .

BIBLIOGRAPHY . . . . . . . . . . . . . . . . . . .

APPENDICES

APPENDIX A - Flow Control and Ionization . . . . . . .

APPENDIX B - Contact Angle . . . . . . . . . . . .

APPENDIX C - Kelvin Equation . . . . . . . . . . . .

APPENDIX D - Particle Diameter Measurements . . . . . . 


\section{LIST OF TABLES}

TABLE

PAGE

I Particle Diameters for Experiment A . . . . . . . . . 74

II Particle Diameters for Experiment B . . . . . . . 75

III Particle Diameters for Experiment C . . . . . . . 75

IV Particle Diameters for Experiment D . . . . . . . . 76 
LIST OF FIGURES

FIGURE

1. Hysteresis effect for a typical salt . . . . . .

2. Distribution with respect to diameter of number, surface area, and volume for a typical aerosol . . . . . . . . . . . . .

3. Sealed sample holder with environmental cell . . . .

4. Experimental apparatus for in situ observation TEM . .

5. Experimental schematic . . . . . . . . .

6. Particle generation and collection equipment .....

7. Hydration sequence for experiment A . . . . . . . .

8. Particle diameter as a function of time for

experiment A . . . . . . . . . . . . .

9. Particle surface area as a function of time

for experiment A..............

10. Particle volume area as a function of time for experiment A . . . . . . . . . . . .

11. Reference identification of particles by number

for experiment B. . . . . . . . . . . . .

12. Reference identification of particles by number

for experiment C . . . . . . . . . . .

13. Hydration sequence for experiment B showing hysteresis effect ............. 
14. Particle diameter as a function of time for experiment B . . . . . . . . . . . . . . .

15. Particle surface area as a function of time

for experiment B . . . . . . . . . . . . .

16. Particle volume as a function of time for

experiment B . . . . . . . . . . . . . . .

17. Hydration sequence for experiment $C$ showing

small particle hydration . . . . . . . . .

18. Particle diameter as a function of time for

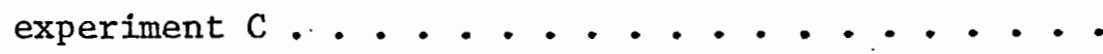

19. Particle surface area as a function of time

for experiment C (larger particles) . . . . . .

20. Particle volume as a function of time for

experiment C (larger particles . . . . . . .

21. Particle surface area as a function of time

for experiment C (smaller particles) . . . . . .

22. Particle volume as a function of time for

experiment C (smaller particles).........

23. Hydration sequence for experiment D . . . . . . .

24. Particle diameter for experiment D...........

25. Particle surface area for experiment D . . . . . .

26. Particle volume for experiment D . . . . . . . .

27. Graph of Kelvin equation and solvent effect 
28. Equilibrium Supersaturation (Kbhler curves) . . . . . 40

29. Equilibrium vapor pressure over bulk surface . . . .

30. Droplet evaporation sequence for contact angle

31. Contact angle schematic . . . . . . . . . . .

32. Contact angle droplet . . . . . . . . . . .

33. Salt crystal and its spherical envelope . . . . . . 68

34. Diagram for Kelvin equation . . . . . . . . . . 70 
INTRODUCTION

The growing concern for our environment in this decade is in part responsible for the current renewed interest in aerosols and atmospheric particles. This concern was expressed at the second Clean Air Congress, IUAPPA, 1970, where on a global scale it was recognized (1) that approximately 75 percent of the total mass of atmospheric aerosol arises from natural and anthropogenic primary sources such as dust raised by wind (20 percent), sea spray (40. percent), forest fires (10 percent), combustion and other industrial operations (5 percent). It was further perceived that secondary sources, usually involving chemical conversion, are 25 percent globally but increase to 40. percent for the continental tropospheric aerosol. Typically these particles follow a log-normal distribution of occurrence with respect to.particle diameter (2). The thrust of current interest is in the smaller ( $<1 \mu \mathrm{m}$ diameter) particles.

More specifically numerous investigators are giving attention to those particles that serve as condensation nuclei for water vapox in the atmosphere. Such processes are suggested (3) to be of concern in air.pollution, visibility, microwave propagation, aircraft icing, fog formation, artificial weather modification, and cloud physics in general. In consideration of the above influences, clearly, hygroscopic particles and deliquescent salts will be of greatest interest. As a major contributor, it is natural that sea spray should be a focus for attention, and with $\mathrm{NaCl}$ as its primary salt, it is not surprising 
that it should have been exposed to a great amount of experimental investigation.

It is known that $\mathrm{NaCl}$ and most inorganic salts exhibit rapid deliquescence at a certain critical humidity (4) (depending on the salt) as opposed to a hygroscopic particle that grows continuously and smoothly with increasing humidity. Furthermore, experimental observations by Orx et a1. $(5,6)$, Twomey (7), and Tang et al. $(4,8)$ demonstrate that evaporation of deliquescent salts takes place at substantially lower humidities than condensation, resulting in the so-called "hysteresis effect" (Fig. 1) for particle growth as a function of humidity. Recent work (4) (1977) by I.N. Tang and other workers, such as that of Winkler (17) (1973) on mixed salts more typical of those found in the atmosphere, shows that this phenomenon is more complicated than for pure salts. Their observations relate this to the variation in solubilities and activities for the multicomponent system.

In the elucidation of this process and its relation to the above-mentioned "hysteresis effect," the question of particle size is critical. Properties of small droplets differ from those in the bulk phase in several respects. These will be discussed in some depth later in this treatise. Briefly, one must consider the change in vapor pressure due to surface curvature (Kelvin effect), the change in vapor pressure due to solubility (Raoult law), and the change in solubility due to curvature. These effects are quite small $(<1$. percent) for particle diameters greater than $1 \mu \mathrm{m}$ but increase significantly when diameters approach $0.5 \mu \mathrm{m}$.

The significance of particles in this size range that are derived 
from sea spray becomes apparent in the 1ight of measurements made by Priening et a1. in 1966 (9). Their results indicate that for particles produced by air blast nebulization, or bursting bubbles, approximately 75 percent have diameters less than $0.2 \mu \mathrm{m}$. This would indicate that by fax the greatest number of nuclei are formed well below the resolution of optical microscopy and span the range of sizes where the above-mentioned curvature effects become considerable.

In assessing the importance of a given size range of particles, it is important to know what properties one is considering as a function of particle diameter. Figure 2 shows a plot of number density, surface area, and volume as a function of diameter for a typical log-normally distributed aerosol. Each characteristic reveals features absent in the others. The bimodal distribution of volume (or mass) has been experimentally demonstrated by Tang et al. (8), using a mobility separation. He finds about two-thirds of the particles in the first (small diameter) mode and about one-third in the second (Iarge diameter) mode. Using this fraction for a rough estimate and the information on the relative mass of salt spray (40, percent of global aerosols with 75 percent less than $0.2 \mu \mathrm{m}$ diameter), we obtain a global mass contribution of somewhat less than 20 percent attributable to such particles.

Even if this percentage drops by a factor of three or four over the continents, it should be clear that, with the characteristic of these condensation nuclei mentioned above, they can play an exceedingly important role in the atmosphere. This is even more apparent when one realizes that concentrations of condensation nuclei per unit volume in clouds far exceed the typical concentration of water droplets found in 


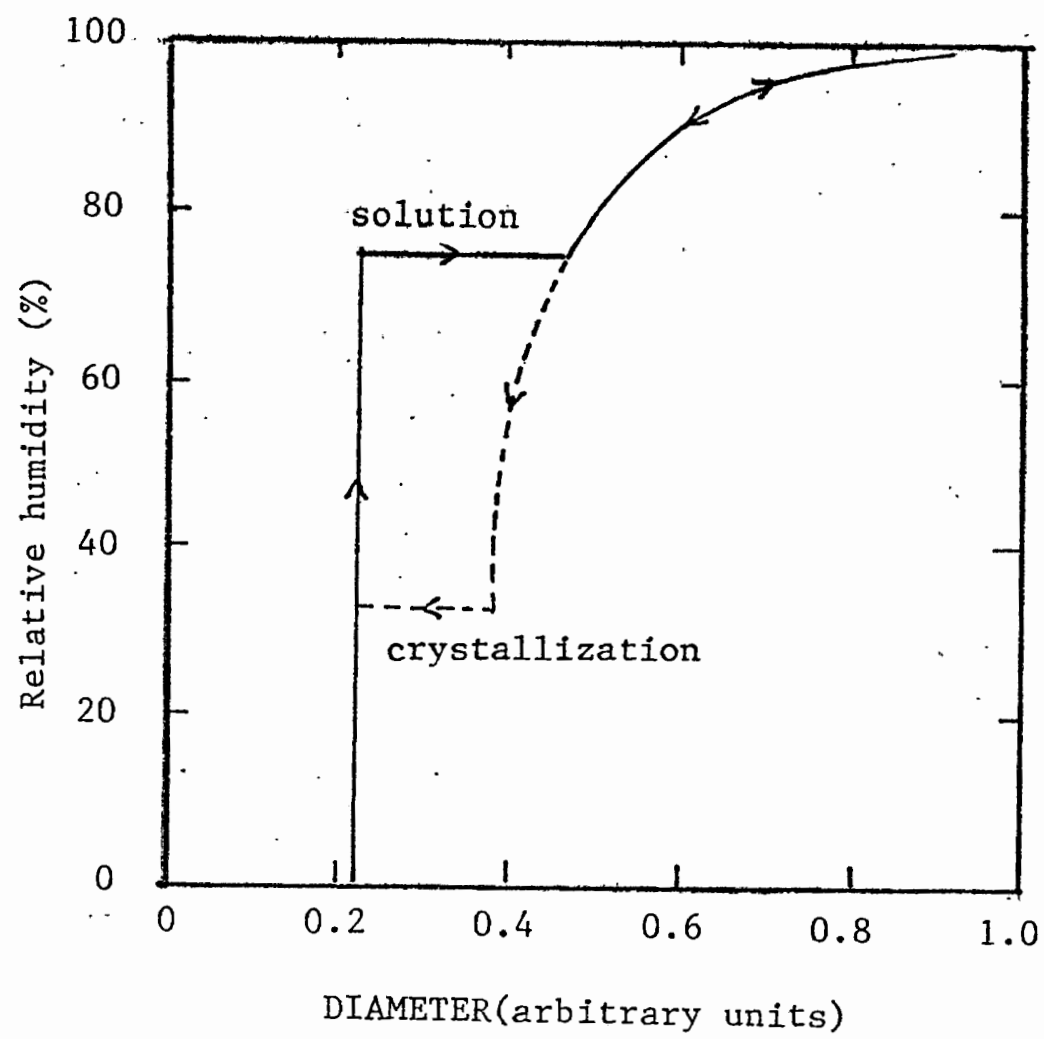

Figure 1. Hysteresis effect for a typical salt.

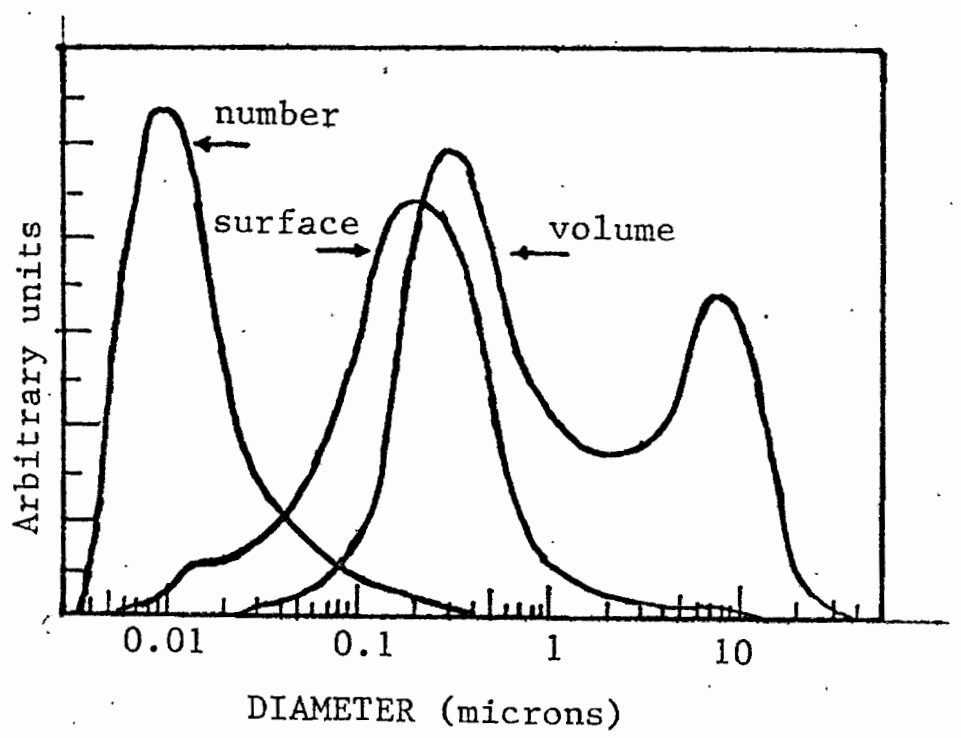

Figure 2. Distribution with respect to diameter of number, surface area, and volume for a typical aerosol. 
clouds (10). Hence a proportionally small concentration of the more active deliquescent particles can play a disproportionate role in condensation phenomena at less than 100 percent relative humidity.

Once hydrated at their critical relative humidity, these particles can continue to grow via general condensation mechanisms. In addition to the above-mentioned influences of such particles, there is significant current interest in the chemical reactions that can transpire in the water envelope once it is formed. Some of these processes are discussed by Cadle (11) and emphasis is placed on reactions of oxides of nitrogen and sulphuric acid in the water droplets. Such a process could lead to the production of $\mathrm{HCl}$, nitrates and sulphates. Ammonia and hydrogen sulphide are also known to be reactive with these particles. It is significant that Cadle and other workers (11) found reaction rates for these constituents to be orders of magnitude faster in the liquid. phase than would be expected in the gas phase. Cadle and others also found relative humidity to be a major factor in the percent of chloride converted to $\mathrm{NO}_{\mathrm{x}}$ reactions. Similarly, Goetz and Pueschel $(12,13)$ observed a complicated dependence of several photochemical reactions on relative humidity.

Considering the relevance of these small deliquescent particles and both the theoretical and experimental uncertainties in their dynamic and reactive properties, there exists a real need to observe such particles in dynamic interaction with their environment. A possible approach was presented by Wei Chang and Parsons (14) in 1974 using an electron microscope environmental chamber for their study of homogeneous nucleation of water droplets. Although their report was of a preliminary 
nature and their results limited, they indicated that the approach could be successfully extended.

In view of the above it was decided to construct a special environmental cell to be used in the electron microscope to examine closely and quantitatively the dynamics of small aerosol particles. For reasons mentioned earlier, the effects of humidity on condensing nuclei were of specific interest. In order to assess the utility of the electron microscope for this type of work and to examine possible beam effects, it was decided to observe directly the hydration and dehydration of $\mathrm{NaCl}$ particles. This choice was made because these. particles have been well examined with less direct methods (4-8) and, therefore, this available literature could assist in characterizing the technique. Furthermore, the results would be of essential utility to more extensive experiments planned on the kinetics of similar aerosols in mixed atmospheres. Lastly, the increased.power and resolution of the electron microscope, over standard optical techniques, was hoped to reveal directly hitherto unobserved phenomena at very small particle diameters. 
EXPERIMENTAL

\section{EXPERIMENTAL SITUUATION}

In order to provide a basis for a series of reproducible experiments, it was decided to collect six identical samples of $\mathrm{NaCl}$ particles. This was accomplished by using a one percent $\mathrm{NaCl}$ solution in a De Vilbiss nebulizer to generate droplets that upon dehydration were impacted onto suitably prepared electron microscope grids. Most particles so produced had mean diameters ranging from 0.1 to 1 microns.

The grids used were obtained from the Ernest F. Fullam Co., Inc. and were a copper mesh (400 openings/inch) of $2.3 \mathrm{~mm}$ diameter coated with superimposed layers of formvar, nitrocellulose, and silicon monoxide of approximately $400 \dot{A}$ total thickness. This composite provided both a substrate for the particles and an impermeable membrane capable of sustaining a pressure differential across it in excess of 40 torr. Two such grids separated by a compression spacer (Fig. 3 ) served to create a chamber (hereafter referred to as a cell) with the bottom grid supporting the $\mathrm{NaCl}$ crystals.

After alignment of upper and lower grids the cell was clamped together and isolated from the vacuum of the electron microscope (HITACHI HU $125 \mathrm{C}$ ) by means of a specially fabricated holder (Fig. 3 ). The holder also serves to transport gases to and from the cell 


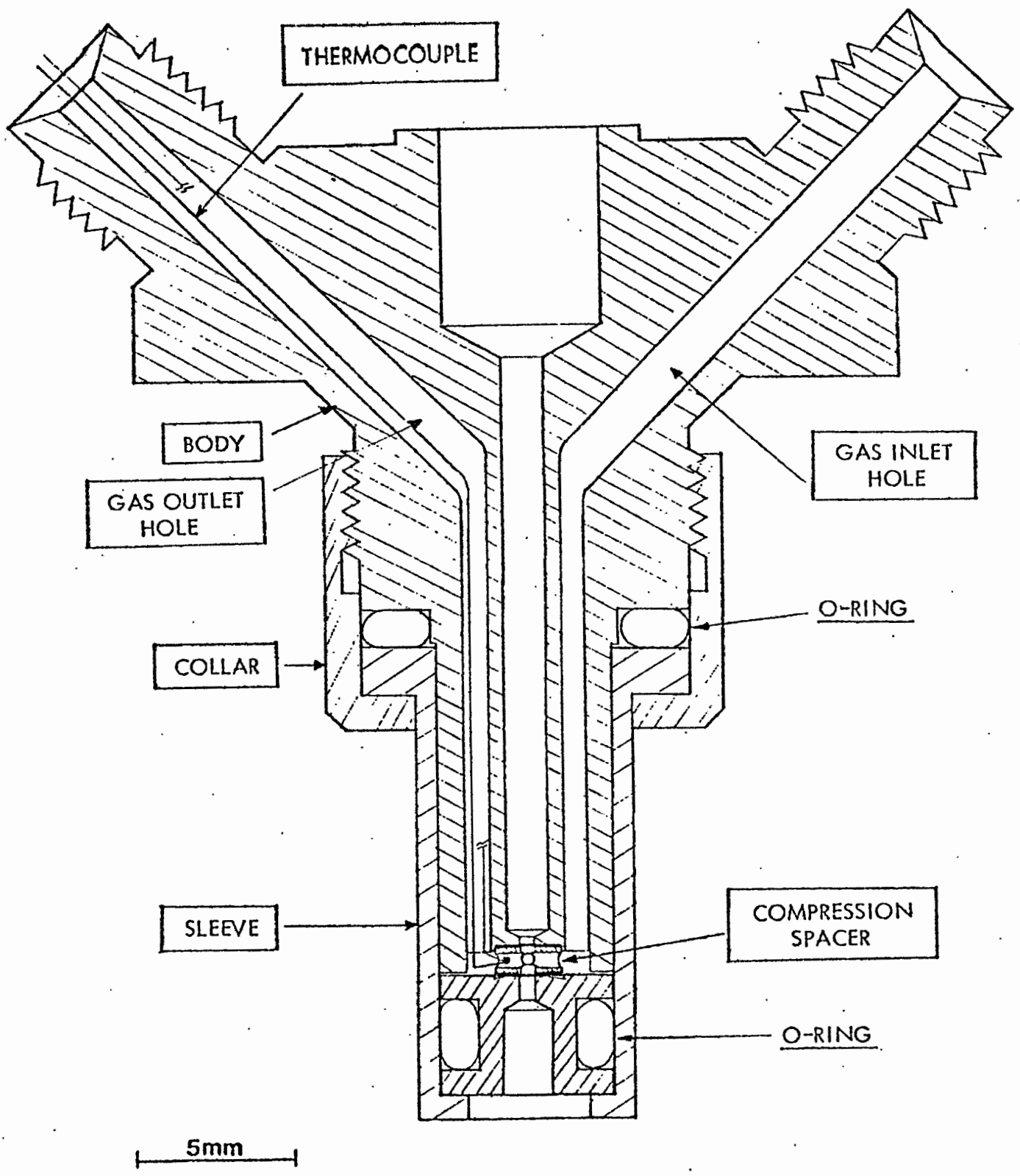

Figure 3. Sealed sample holder with environmental cell in place. (Thin film E.M. grids are above and below the compression spacer.) 
and permits placement of a thermocouple in the gas flow as it exits the cell. The vertical axis of the holder is bored out to permit passage of the electron beam which penetrates the cell and compression spacer through a $0.5 \mathrm{~mm}$ diameter opening. This results in an enclosed space $1 \mathrm{~mm}$ high and $0.25 \mathrm{~mm}$ in radius accessible to the beam (VOLUME $=0.2 \mathrm{~mm}^{3}$ ).

The sample holder was dimensioned to fit in the stage of the microscope, which could be manipulated for azimuth and tilt so as to permit unobstructed beam passage. The standard specimen loading arm was removed and replaced with a port allowing the passage of gas to and from the cell. The gas handling system shown in Fig. 4 is schematically represented in Fig. 5 showing the operational relationships for the regulatory, delivery, and monitoring components. Images of the sample could be viewed on the phosphor screen or alternately delivered to the image intensifier for display on a T.V. monitor attached to the microscope. This permitted direct hookup to a video-tape recording system that recorded each experiment on tape. Later experiments also used a strip chart recorder to monitor pressure and temperature continuously in synchronization with the video display. A taping speed of 30 frames/sec. allowed growth measurements to be taken from the tape with a time resolution of $1 / 30$ th sec. real time. Most measurements were taken from a 24 inch T.V. monitor that had not been corrected for vertical or horizontal distortion. 


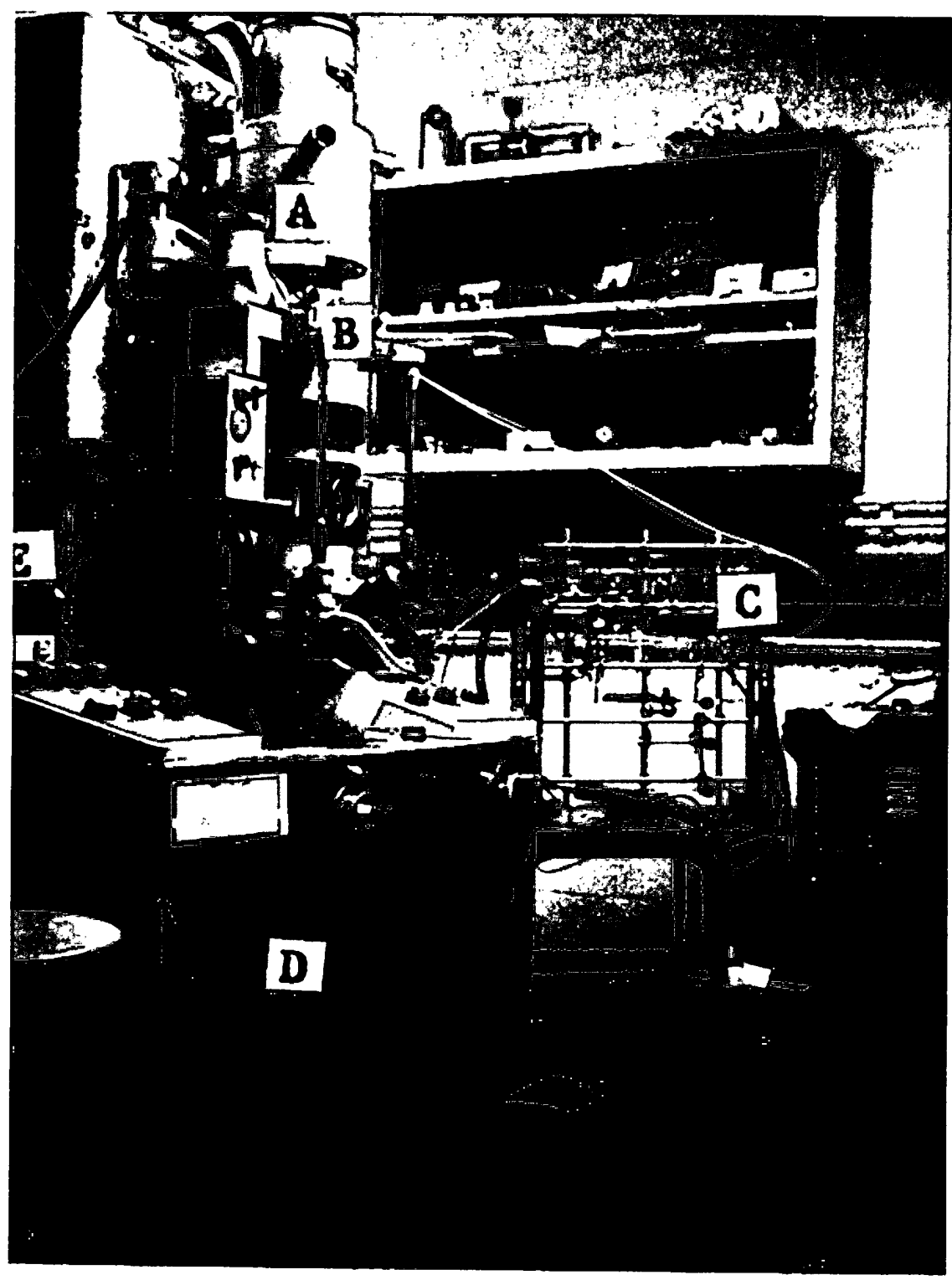

Figure 4. The experimental apparatus for in situ observation by T.E.M.

A. Hitach 125 Microscope

B. Specimen stage with environmental chamber situated inside

C. Glass gas handling system with two connecting tubes

D. Image intensifier

E. T.V. Aisplay 


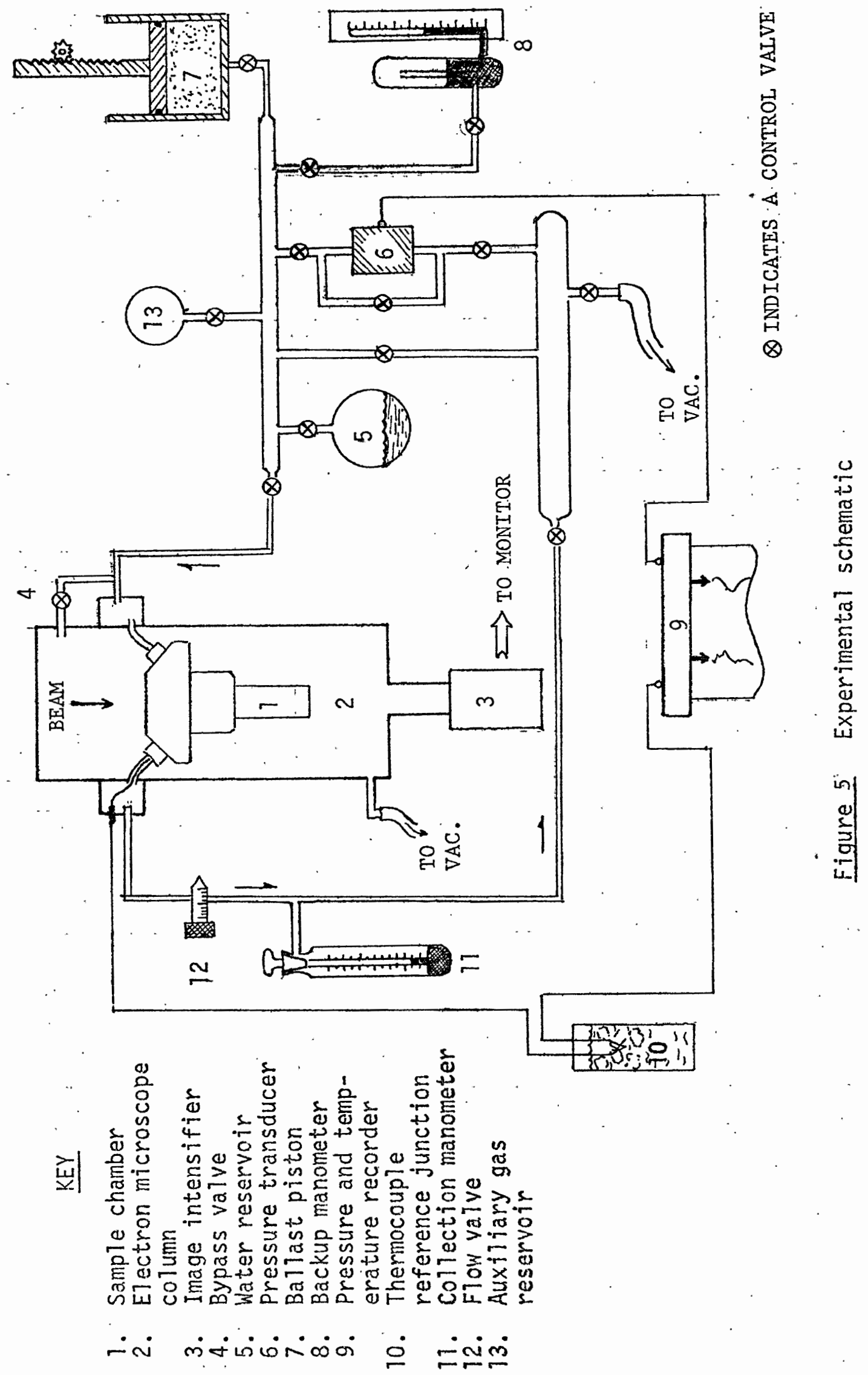




\section{EXPERIMENTAL PROCEDURE}

Following preparation, the sample grid was installed in the holder such that upper and lower grid openings were aligned and centered. The sample holder was then placed in the microscope and the system evacuated (Fig. 5 ). A bypass valve connecting the cell interior to the microscope column was open during evacuation to avoid a large pressure differential over the cell grids. The gas handling system was also evacuated prior to admission of water vapor at room temperature. The valve to the water flask was then closed and the ballast piston was adjusted to reduce the vapor pressure to approximately 5 torr. Pressure was measured with a variable reluctance pressure transducer (model CJ3D, C.J. Enterprises) in the feed system and later with an auxiliary backup manometer.

Prior to turning on the beam, the bypass valve to the column was closed and water vapor at $\sim 5$ torr was admitted to the cell in order to minimize any heating of the sample by the beam. Gas flowing through the cell was regulated with a flow valve (Whitey SS R52-A) and collected in an evacuated manometer. The valve was adjusted to provide a high flushing rate without a significant pressure drop over the cell (See Appendix A for calibration and analysis). Under actual working conditions, gas flow velocity in the cell was less than $10 \mathrm{~cm} / \mathrm{sec}$ and ionization by the beam amounted to approximately $<10^{7}$ at any instant compared to $\sim 10^{14}$ water vapor molecules (See Appendix A ).

Particle sizes were recorded on electron micrographs prior to switching to video display, which made possible the use of reduced beam intensities. Once on video display, the vapor pressure was gradually increased while the sample was continually monitored. At a certain 
critical humidity the particles could be observed to hydrate and reach an equilibrium droplet diameter in a matter of seconds. Suitable manipulation of pressure enabled observation of a variety of effects that could later be interpreted quantitatively.

\section{SAMPLE COLLECTION}

The collection of fine ( $<1 \mu$ diameter) aerosol particles in this experiment was accomplished using a modified Anderson type cascade impactor (Fig. 6 ) on loan from the Oregon Graduate Center. Although numerous superior methods exist for the collection of these particles, ( 3 ) this method was chosen as the impactor was available and was considered sufficient for the preliminary nature of this investigation.

A recent article by Newton, Raabe and Mokler (15) evaluates the critical parameters for impactor performance. An abbreviated listing of the factors they consider important to collection efficiency are:

(a) linear velocities of gas in each stage.

(b) jet openings (shape and size and sticking factor).

(c) aerosol particle shape.

(d) particle size.

(e) particle density.

(f) slip flow correction.

(g) gas viscosity.

(h) jet-impaction plate separation.

(i) jet throat length.

(j) Reynolds number.

On the basis of the equations presented in their publication, it would appear possible to design a system to collect particles specifi- 
cally in the 0.01 to 1 micron range of interest. However, such an option was not available and efforts were made to utilize equipment and materials at hand. Rather than regulating and calibrating apparatus to deliver particles of known distribution and velocity, an experimental approach was used to obtain suitable deposits.

The major elements of the system employed are illustrated in Fig. 6 . The impactor itself consists of five stages separated by teflon spacers and stainless steel baffles with jet orifices. Orifices are circular and decrease to 0.001 inch diameter above the final collection stage. This stage was modified to accept an electron microscope grid retainer (Fig. 6 ) designed to hold six grids. This permitted collection of six samples deposited under identical conditions for use in subsequent experiments.

A modified De Vilbiss type nebulizer'is also illustrated in Fig. 6 . This was used with a dry nitrogen carrier gas to generate the aerosol collected in the impactor. The nebulizer was charged with a $1 \%$ 'solution of $\mathrm{AR}$ grade $\mathrm{NaCl}$ dissolved in deionized distilled water. In addition to the apparatus shown in Fig. 6 , it was found necessary to use a hot air blower to preheat the impactor and lines in order to insure total dessication of the aerosol prior to deposition.

Repeated trial situations established the following criteria that resulted in a suitable deposit:

(a) Driving pressure of dry nitrogen carrier gas should result in a light to moderate spray.

(b) Amorphous crystals significantly reduced by preheating impactor and feed lines to $\sim 50^{\circ} \mathrm{C}$. 
(c) Intermittent gentle pulsing of secondary tube on impactor exit varied flow velocity of gas in the impactor. This improved both deposition and distribution.

Deposition characteristics for the six grids prepared were:

1. Preheat lines and impactor for 4 minutes.

2. Open bleed to $1 / 3$ of tube diameter.

3. Attach nebulizer to impactor for 30 seconds.

4. Close bleed line 5 times for $3 \mathrm{sec}$, each time.

5. Repeat 1-4 after relocating grids in order to increase likelihood of a centered deposition on each grid.

The intermittent.pulsing (closing) of the bleed tube had a significant effect on gas velocity through the impactor. This in turn affected several of the collection efficiency parameters and resulted in a suitable distribution of particles.

Once collected the samples were examined under a light microscope to insure that deposition existed in the central viewing field of the grid and then stored under vacuum until use. The particles were too small to resolve clearly but the larger particles provided sufficient interference to indicate the deposition area and distribution density. 

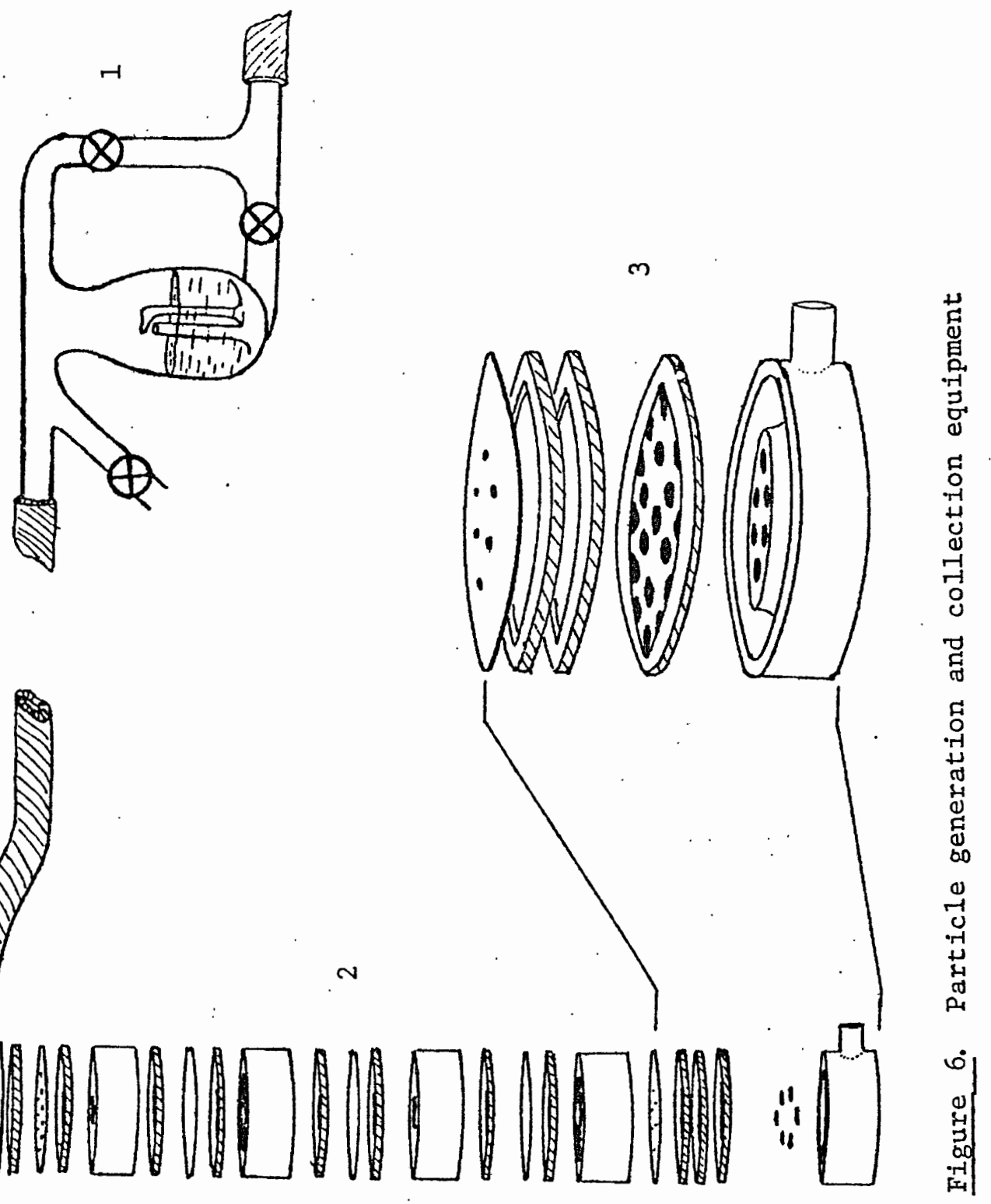

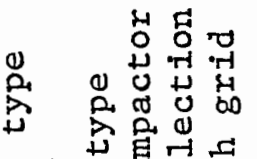

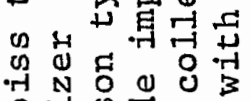

$$
\begin{aligned}
& \text { 州 员年 }
\end{aligned}
$$

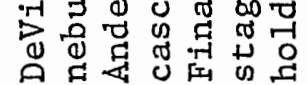

$$
\begin{aligned}
& \dot{\sim} \dot{\sim} \dot{m}
\end{aligned}
$$




\section{EXPERIMENTAL RESULTS}

The series of expeximents performed under the above described conditions were encouraging in that observed effects indicated good potential for this technique. However, failures and problems with pressures, temperature, and vacuum systems plagued many observations. Nevertheless, results were significant and corrections or adjustments were possible in many cases and provided valuable corroboration of earlier observations using less direct techniques. As the nature of the data differs somewhat from experiment to experiment it is most illustrative to analyze them independently.

The first experiments were performed without the benefit of continuous temperature and pressure measurements but they did display the nature of the phenomena observed. Five particles ranging in size from $0.27 \mu$ to $1 \mu$ diameter were observed to grow to spherical droplets with final diameter ranging from $0.60 \mu$ to $2.18 \mu$, respectively. In determining particle sizes it is important to note that the electron microscope provides information about two dimensions only. Therefore, in the case of particles, it was assumed that the third dimension was approximately an average of the other two dimensions. For isolated, apparently cubic particles this assumption is probably valid. For oddly shaped particles and clusters, sizes were arrived at individually. To arrive at volume and surface area growth rates for droplets from diameter measurements, it was necessary to determine the advancing contact angle for the droplet on the substrate. Details of this 
measurement are included in Appendix B and yield a value of approximately $110^{\circ}$ for pure water and $114^{\circ}$ for a saturated droplet.

On the basis of the above measurements, graphs were made of droplet diameter surface area and volume as a function of real time. A table of direct measurements of droplet diameter is included in Appendix B for reference.'

The first successful experiment was performed when neither cell gas temperature nor pressure was well known. A series of six pictures showing qualitatively the hydration phenomena is indicated in Figure 7 and the corresponding growth curves for particle diameters are shown in Figure 8 . From the shape of the particles it is clear that the greatest symmetry and consequently most reliable measurements of original size are expected for particles labeled No. 2 and No. 3

The points at which a spherical cap envelops the particle occur at $\sim 1.5$ times the original particle diameter (see Appendix B) and are indicated by a solid square at the appropriate points on the graphs.

As the diameter of the above mentioned particles exceed the range where the Kelvin or curvature-solubility effects are apparent, we can use Raoult's law, or activity data from $\mathrm{NaCl}$ in solution, to calculate the equilibrium vapor pressure over the surface. It is also of interest to observe the point at which the particle is completely dissolved, assuming an activity coefficient of one and a solubility of $0.36 \mathrm{gm} / \mathrm{cc}$ : (1) $\rho_{\mathrm{s}} \mathrm{V}_{\mathrm{s}}=0.36 \mathrm{gm} / \mathrm{cc} \mathrm{Vsc}$

$$
\begin{aligned}
\mathrm{v}_{\mathrm{S}}= & \text { volume of salt } \\
\mathrm{v}_{\mathrm{sc}}= & \begin{array}{l}
\text { volume of spherical } \\
\text { cap at total } \\
\text { dissolution }
\end{array} \\
\rho_{\mathrm{S}}= & \begin{array}{l}
\text { density of salt } \\
(\mathrm{gm} / \mathrm{cc})
\end{array}
\end{aligned}
$$




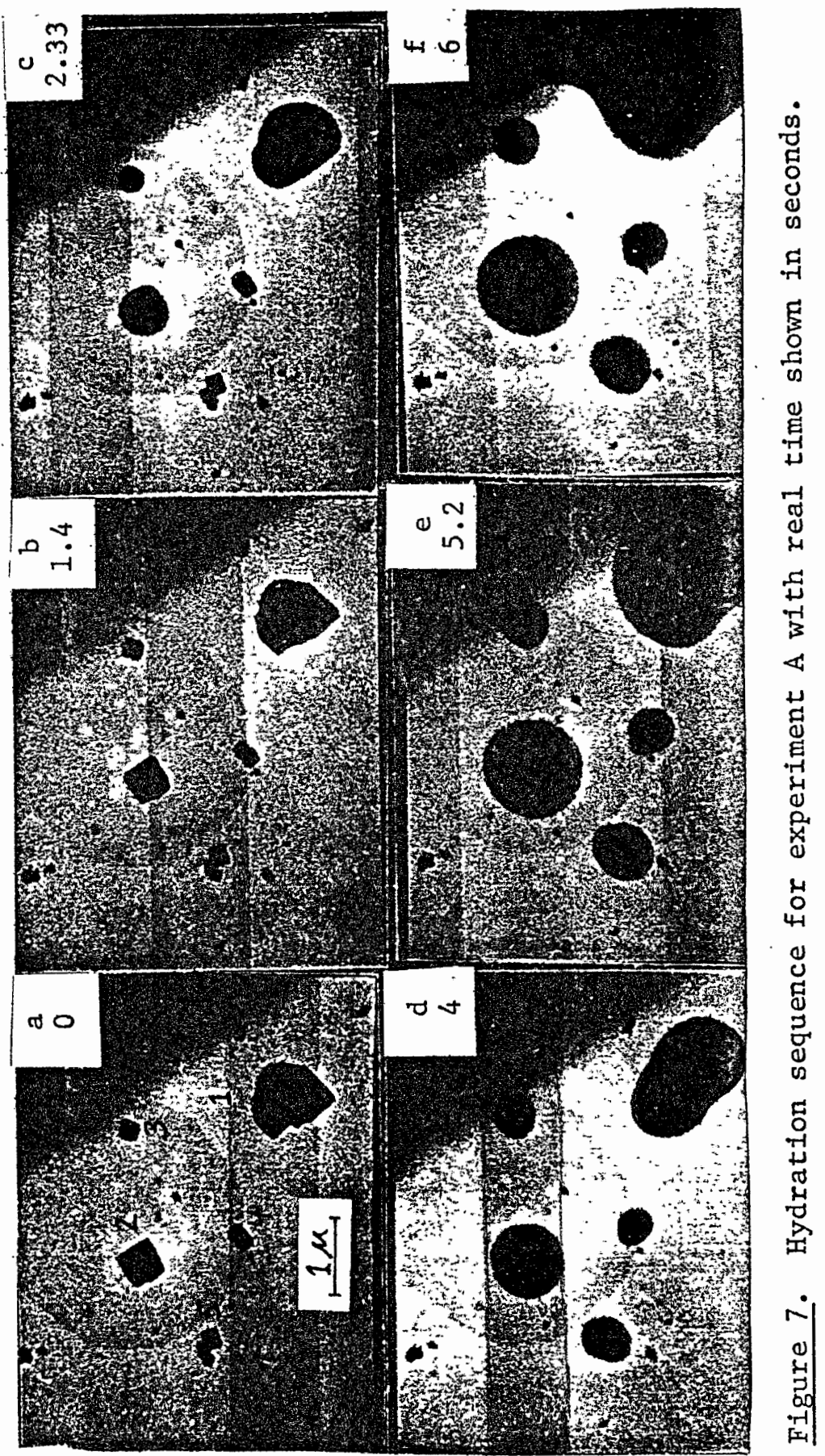




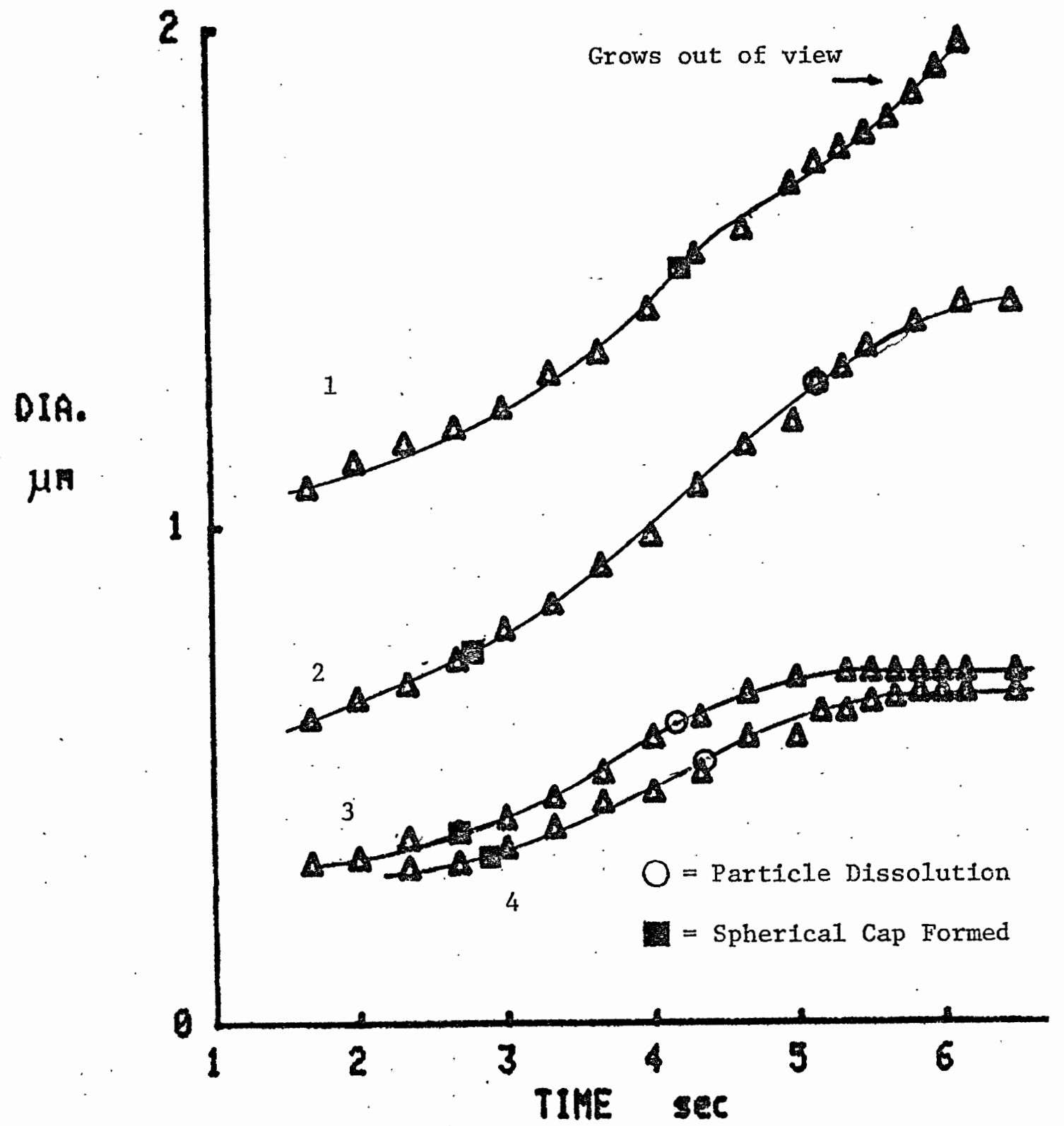

Figure 8. Particle diameter as a function of time for Experiment A. 

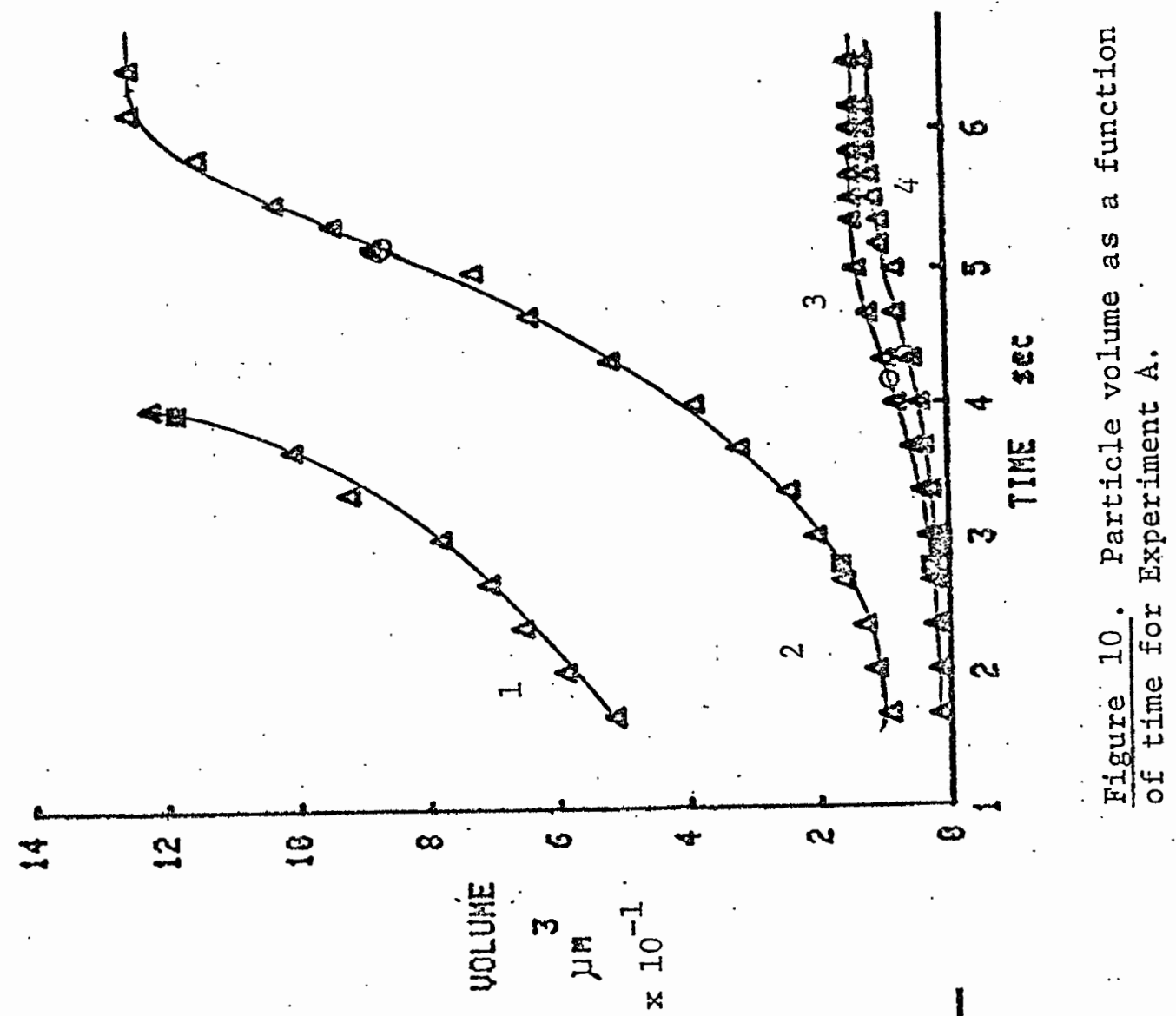

몽 t)

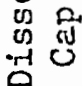
a ग 政
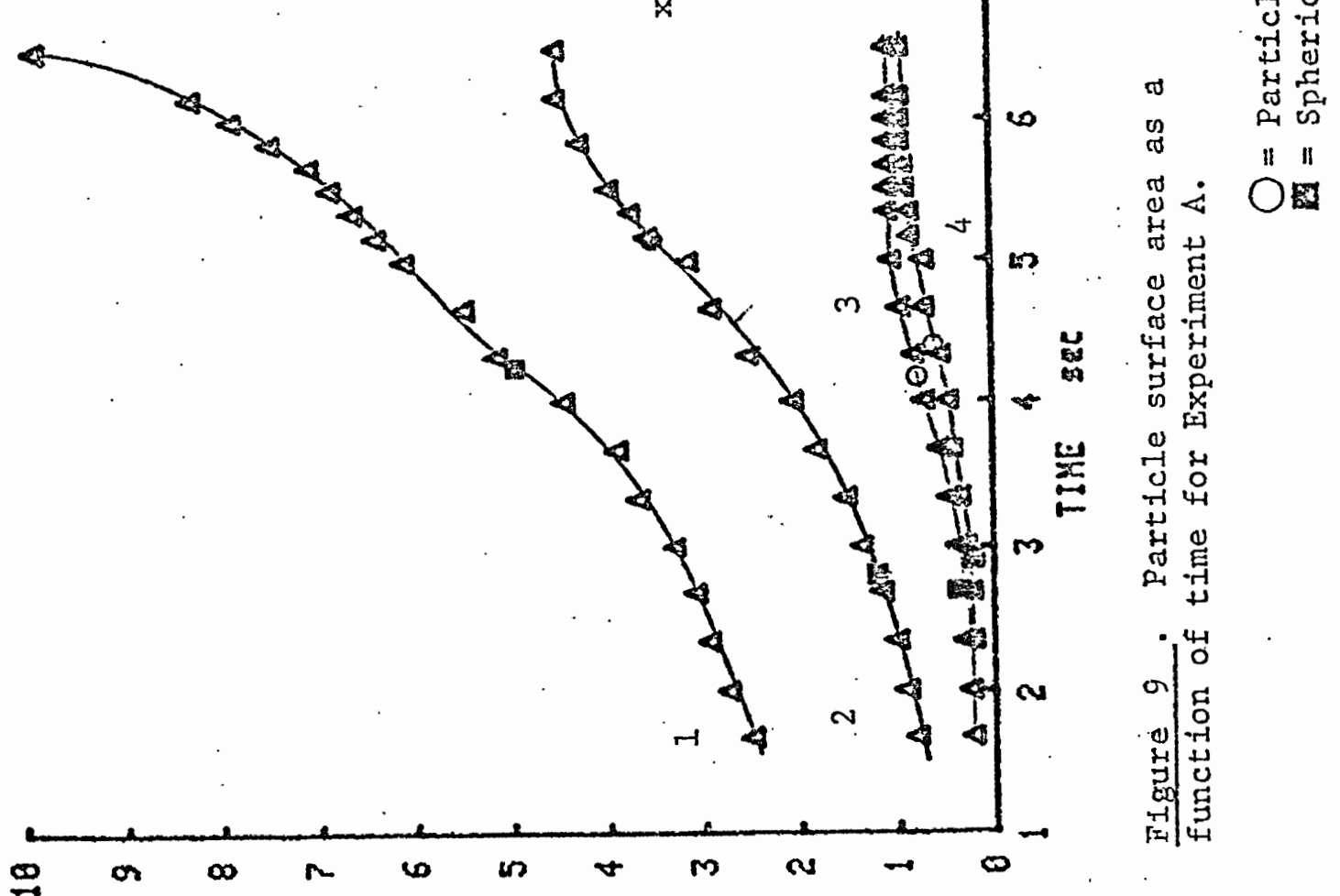

$$
\text { 㟧㗪点 }
$$


Thus:

(2) $\mathrm{V}_{\mathrm{sc}}=6.01 \mathrm{~V}_{\mathrm{s}}$

in terms of diameters we get (see Appendix B).

(3) $d_{s c}=2.45 d_{s}$

$$
\begin{aligned}
& d_{s}=\begin{array}{l}
\text { diameter of salt } \\
\text { crystal }
\end{array} \\
& d_{s c}=\begin{array}{l}
\text { diameter of } \\
\text { spherical cap }
\end{array}
\end{aligned}
$$

The point at which a particle is predicted to go into solution is shown on the graphs by an open circle.

In a similar experiment to the one above, an unexpected

dehydration resulted in the apparent disappearance of several particles in the beam. Only a residual impression remained. Subsequent rehydration resulted in the appearance of numerous small "satellite" droplets in and around the residue in the size range of interest $(<0.1 \mu \mathrm{m}$ diameter). This prompted another test, which was performed more deliberately. Prior to attempting the production of small "satellite" crystals as mentioned above, it was decided to attempt a partial hydration of the crystals in order to examine the "hysteresis effect" under the electron beam. A new grid with a suitable deposit was inserted, and appropriate magnification for viewing was selected. Pressure was increased from a delivery pressure of 5 torr to 12 torr. It was stopped here as inexpected hydration had started at 12 torr. Dropping the pressure back down resulted in recrystallization of the hydrated particles.

After selecting a new opening with a good crystal assortment, the piston pressure was increased until hydration was perceived to start in the cell, and then it was reduced immediately - enough to. 
arrest hydration. Pressure quickly built up again in the cell, and equilibrium was reached. Although the dehydration and rehydration spanned only two seconds, it revealed some interesting results when reexamined frame by frame on the videotape. Some selected frames are included in Figure 13. These indicate that the two smallest crystals remain as spherical droplets while the others temporarily dehydrate back to a crystalline form. This is quantitatively revealed in a graph of particle diameter vs. time (Fig. 14) for Experiment B. This observation is readily accounted for by considering the criteria for the total dissolution for cubic crystals determined above (i.e., $\left.d_{s c}=2.45 d_{s}\right)$. The point where this condition should be met is indicated on Figure 14 (and similar figures) by a circle. Clearly the small crystals (No. 2, No. 5) are in solution before the pressure dropped, while the large one (No. 1) remains only partially dissolved. The dissolution points for No. 3 and No. 4 appear just before the turning point (dehydration) of their respective curves (Fig. 13-16). As dessication did occur, it is 1ikely that the particles had not yet dissolved and there is some inaccuracy in the measurements.

Both particles are off-axis in the viewing field and subject to the greatest distortion, due to spherical abberation of the microscope, T.V. monitor, and camera. Furthermore, the calculated dissolution point presumes accurate measurements of contact angle, particle height, solubility, solution equilibrium conditions and rates. Thus, the $6 \%$ diameter increase over the expected dissolution point for the dehydrating particles No. 3 and No. 4 is not unreasonable.

This observation indicates that the well documented "hysteresis" behavior observed by others (4-8) can be directly monitored in the 


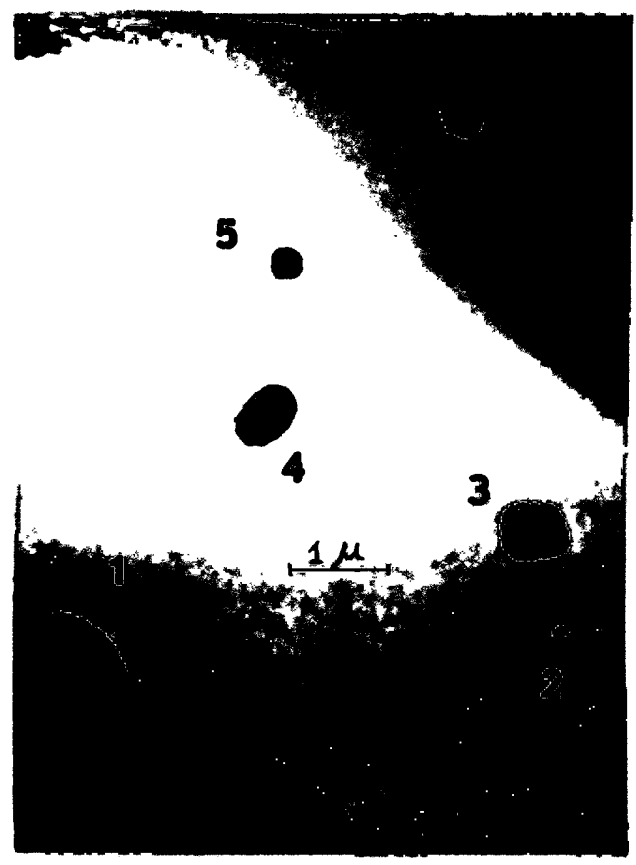

Figure 11. Reference 1dentification of particles by number for Experiment $B$.

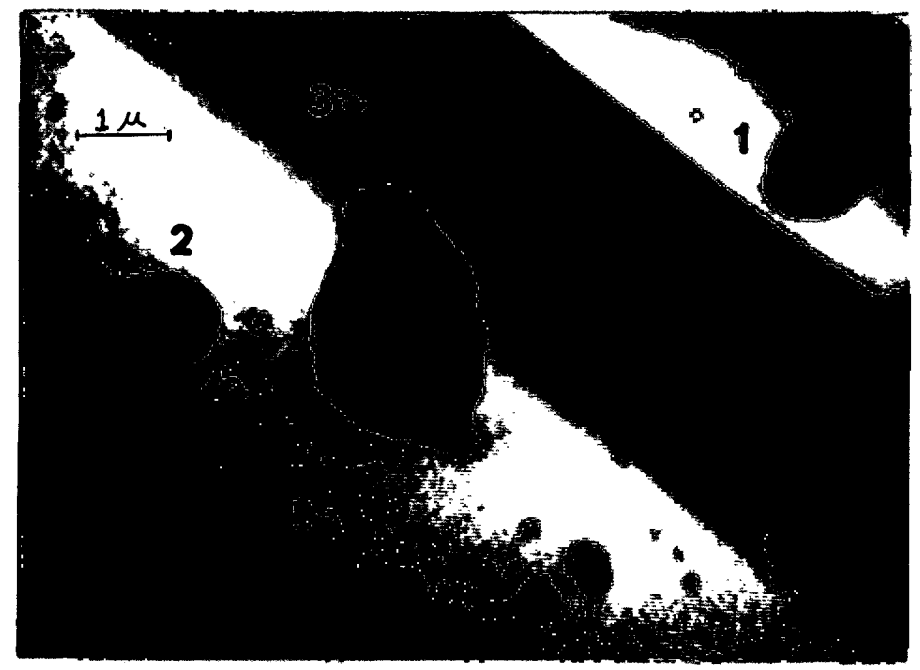

Figure 12. Reference 1dent1fication of droplets by number for Experiment $C$. 


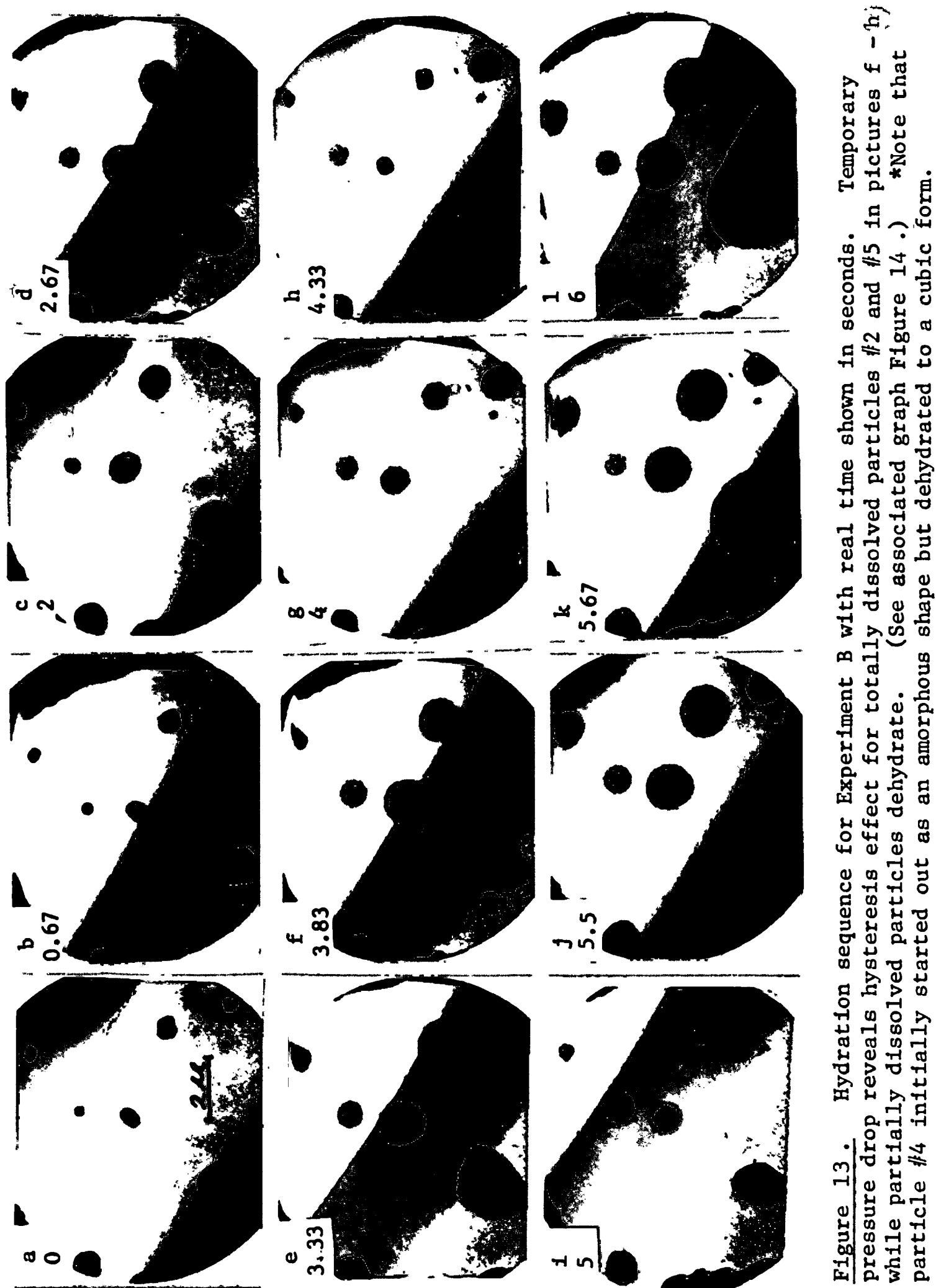




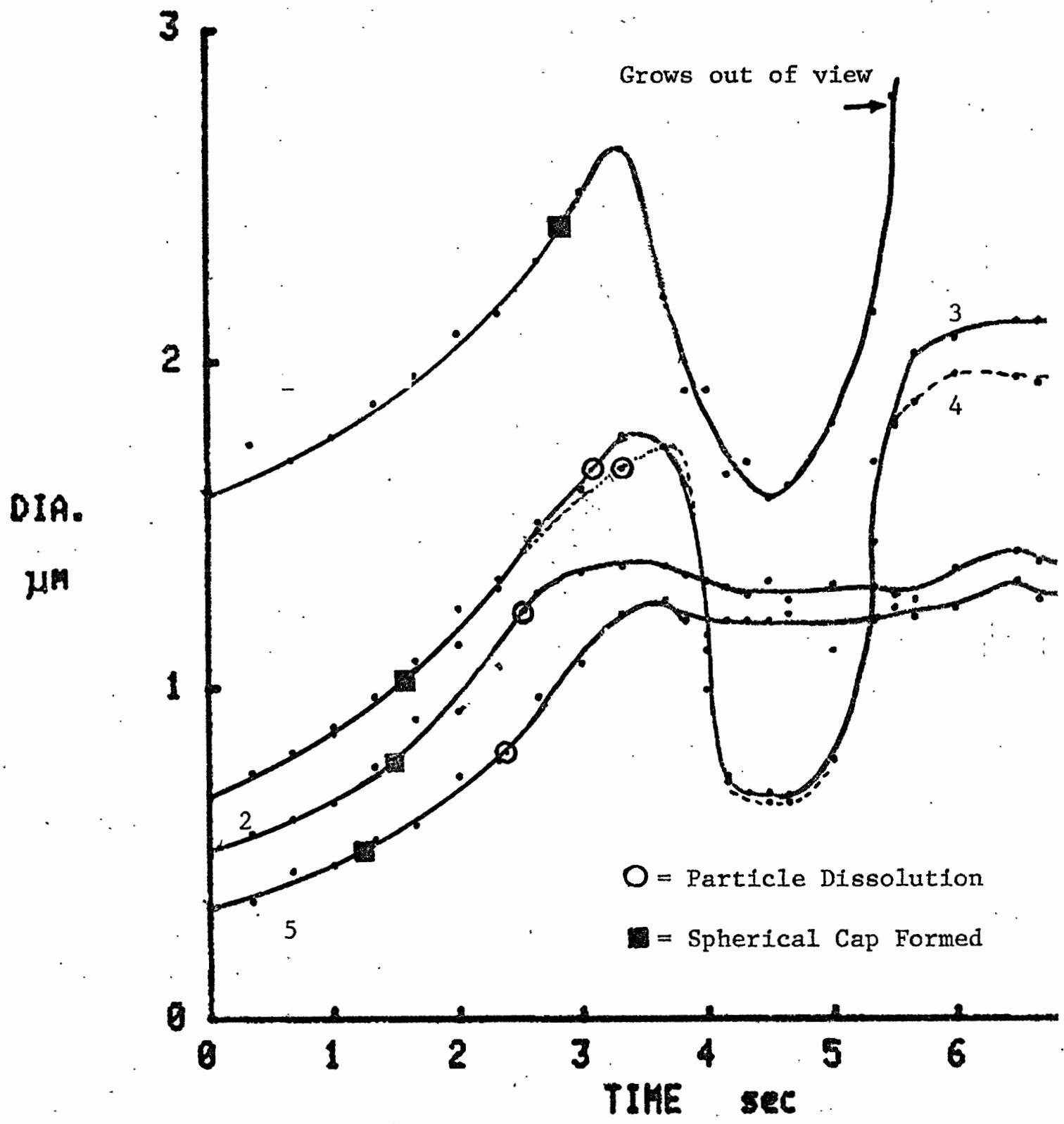

Eigure 14. Particle diameter as a function of time for Experiment $B$. 

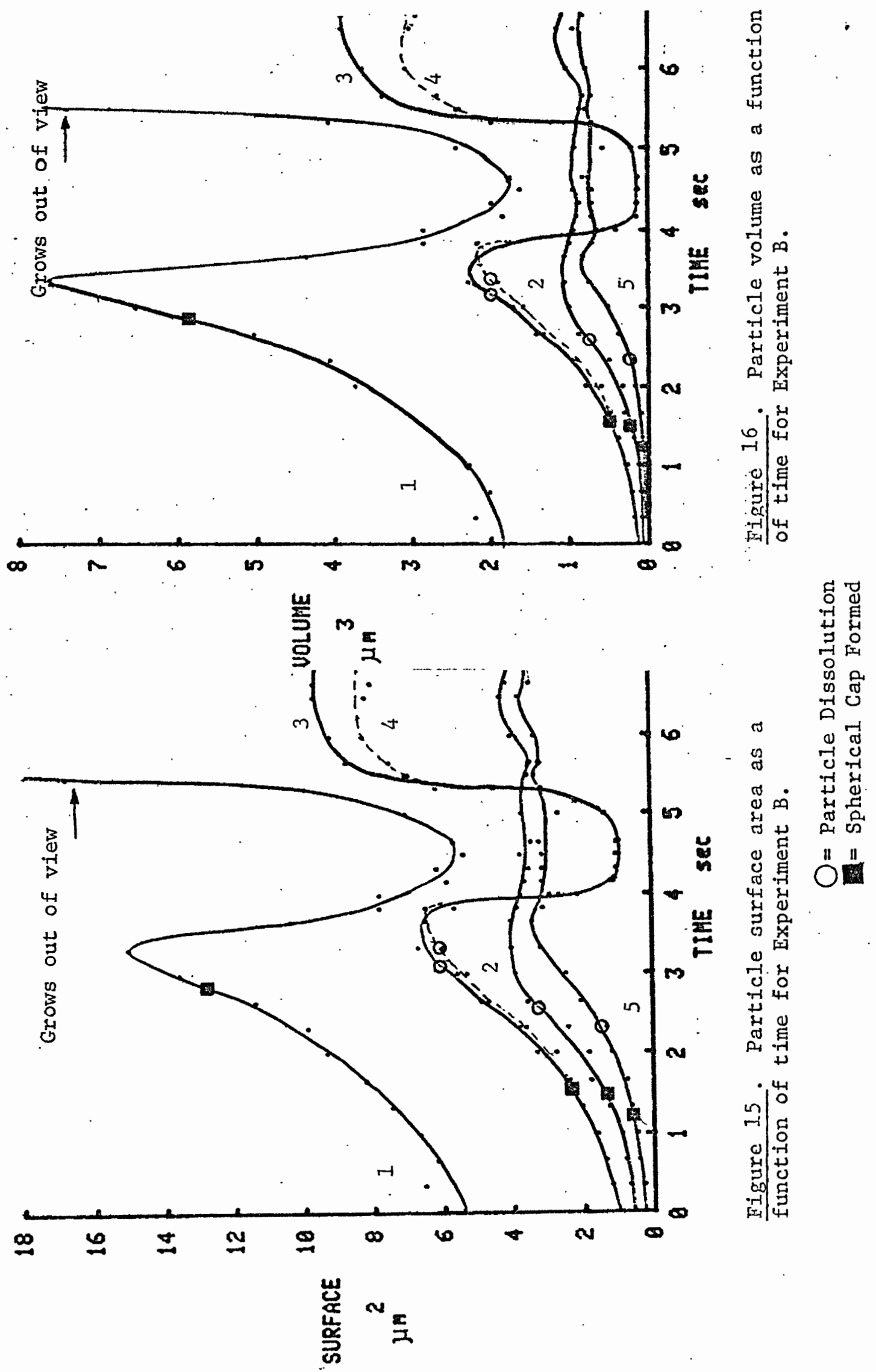
electron microscope. It further substantiates the claim (10) that significant supersaturation is required for nucleation of solute when "seed" crystals are absent in the solution.

In experiment $\mathrm{C}$ a new collection of particles was selected and partially hydrated, then dehydrated in a similar manner to experiment $B$. This time the particles that remained in solution, and did not recrystallize, were not immediately exposed to an increase in relative humidity (pressure). Instead, they gradually "faded" and disappeared in the beam leaving a faint but discernable outline in the shape of the original crystal. Diffraction patterns indicated traces of polycrystalline $\mathrm{NaCl}$ (but with discernable spots in the ring pattern) at these locations.

Once again, the collection was subjected to increasing relative humidity and hydration ensued (Fig. 17). This time, in addition to the rehydration of the remaining original particles, numerous small droplets appear on the background. These droplets form considerably 1ater than the 1arger ones (see Fig. 17). Of the sma11 droplets, the ones that develop earliest and grow largest are seen at those locations previously occupied by a larger "faded" particle.

A regular distribution of many other small droplets developed in regions previously unoccupied. The graph (Fig. 18) of particle diameter shows more accurately the growth of the particles and reveals a similar behavior of both large and small particle measurements with time. Note that evidence, of a vapor pressure drop between $g$ and $j$ in Fig. 17 shows as a "fading" of the smaller droplets. This also corresponds well with a temporary decrease in droplet diameter for the larger particles (Fig. 18-22). 

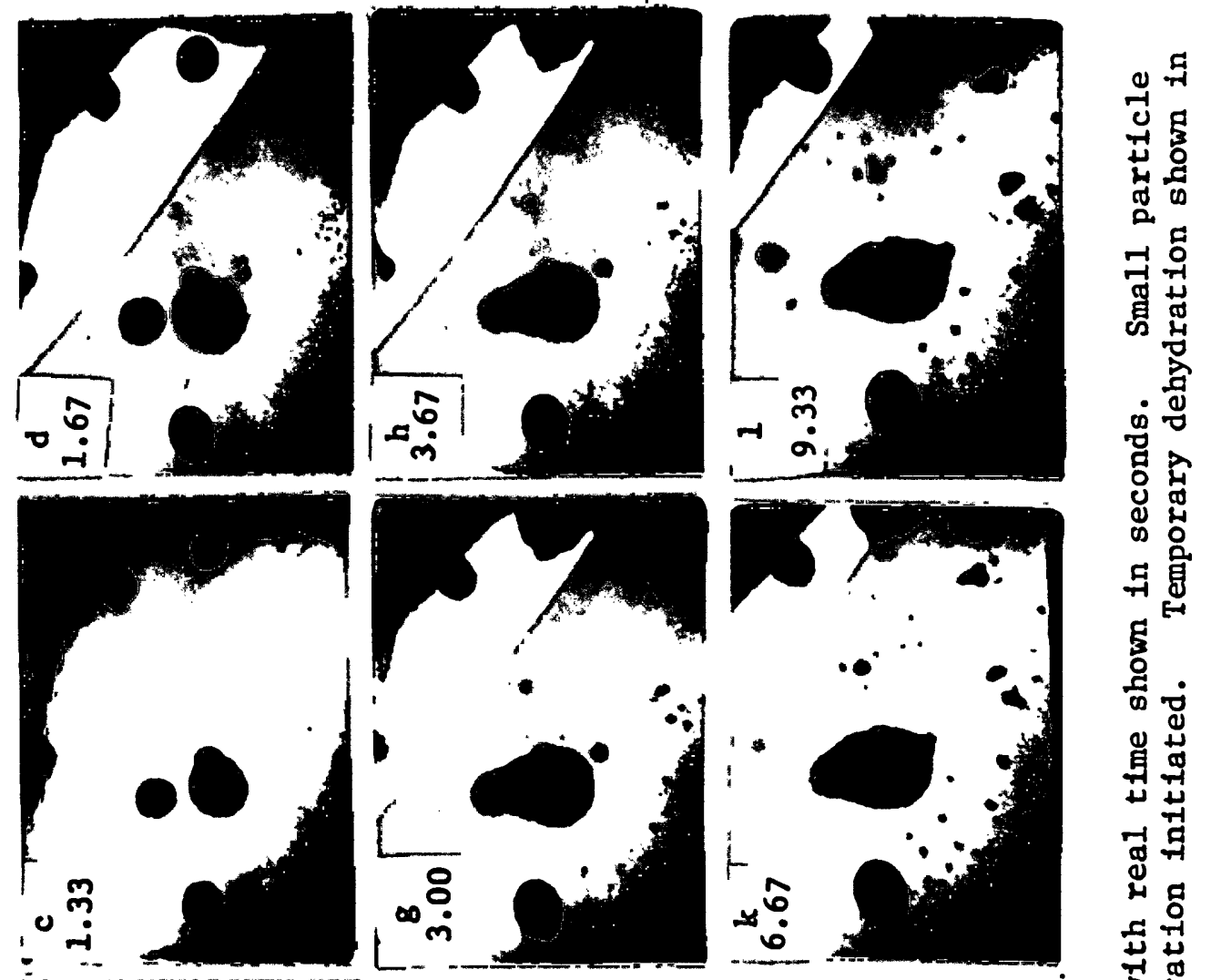

总 㿣 꼄

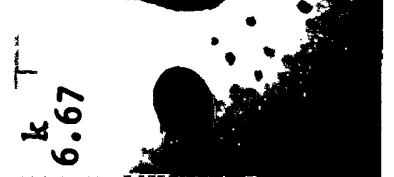

돈듀

운
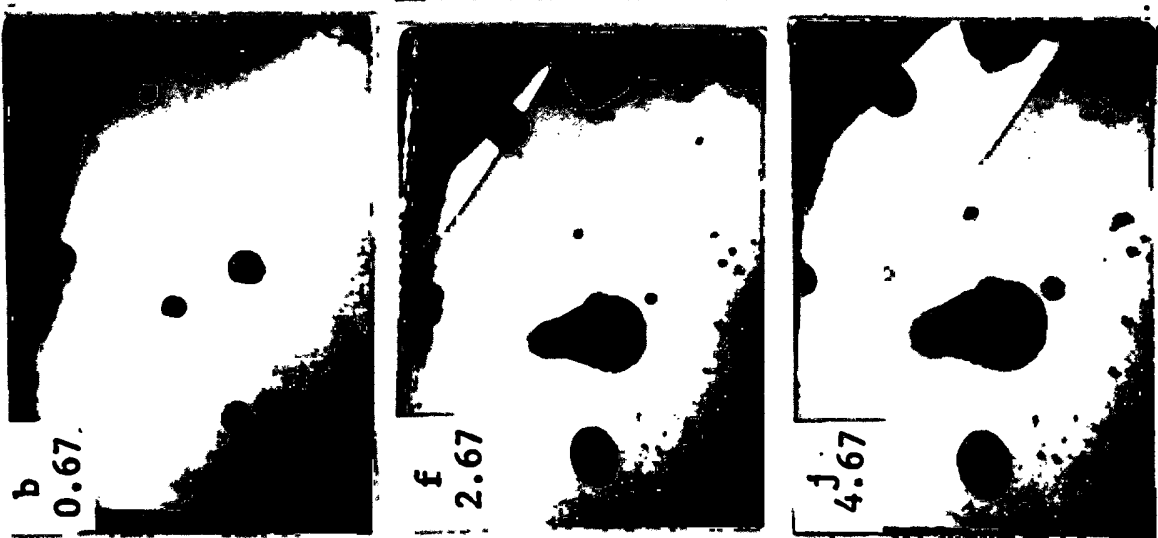

(올

岂鸷?

出 $\infty$

呙恖。

品

400

운

o ${ }^{\prime}$

㟧菌

出出

莒 ๗

(⿻)
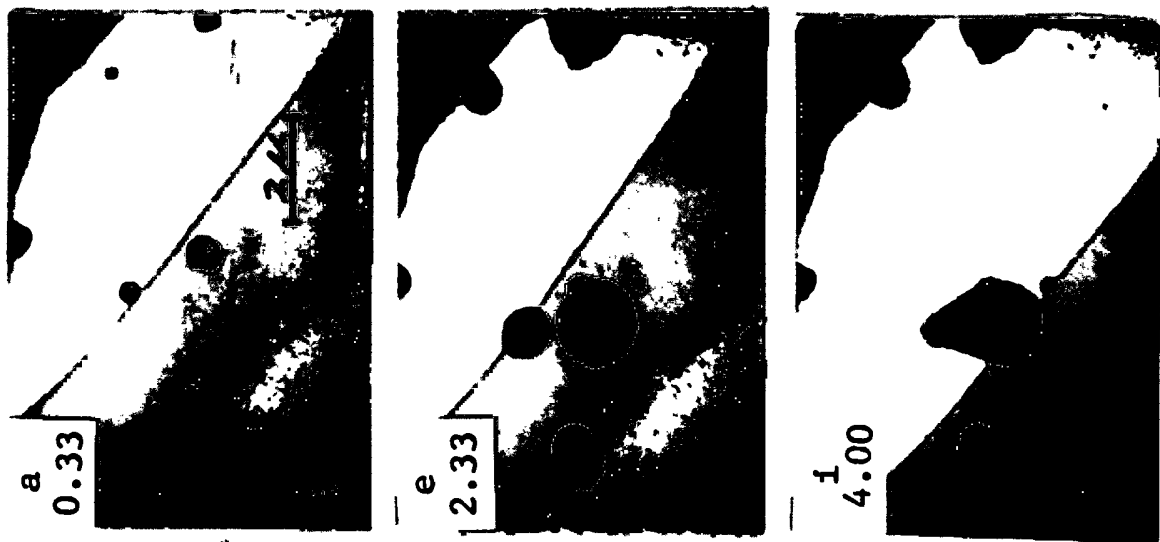

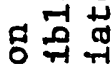

त क

मे

究 $>$

मू

iี ¿ \&

- 茜己

가 है

त्र

क्ष

मु

${ }_{-1}^{\infty}$

年 


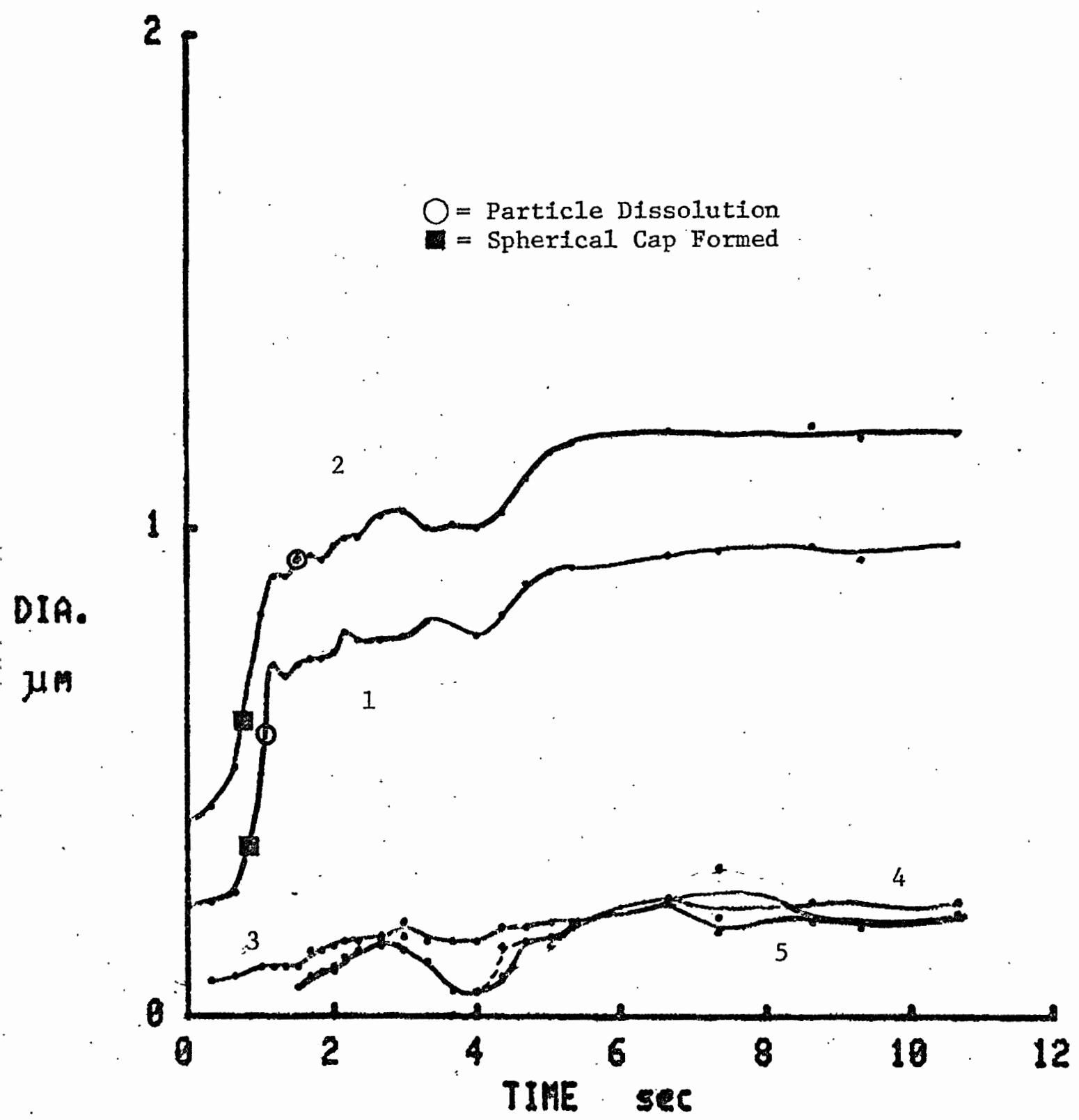

Figure 18. Particle diameter as a function of time for Experiment $C$. 


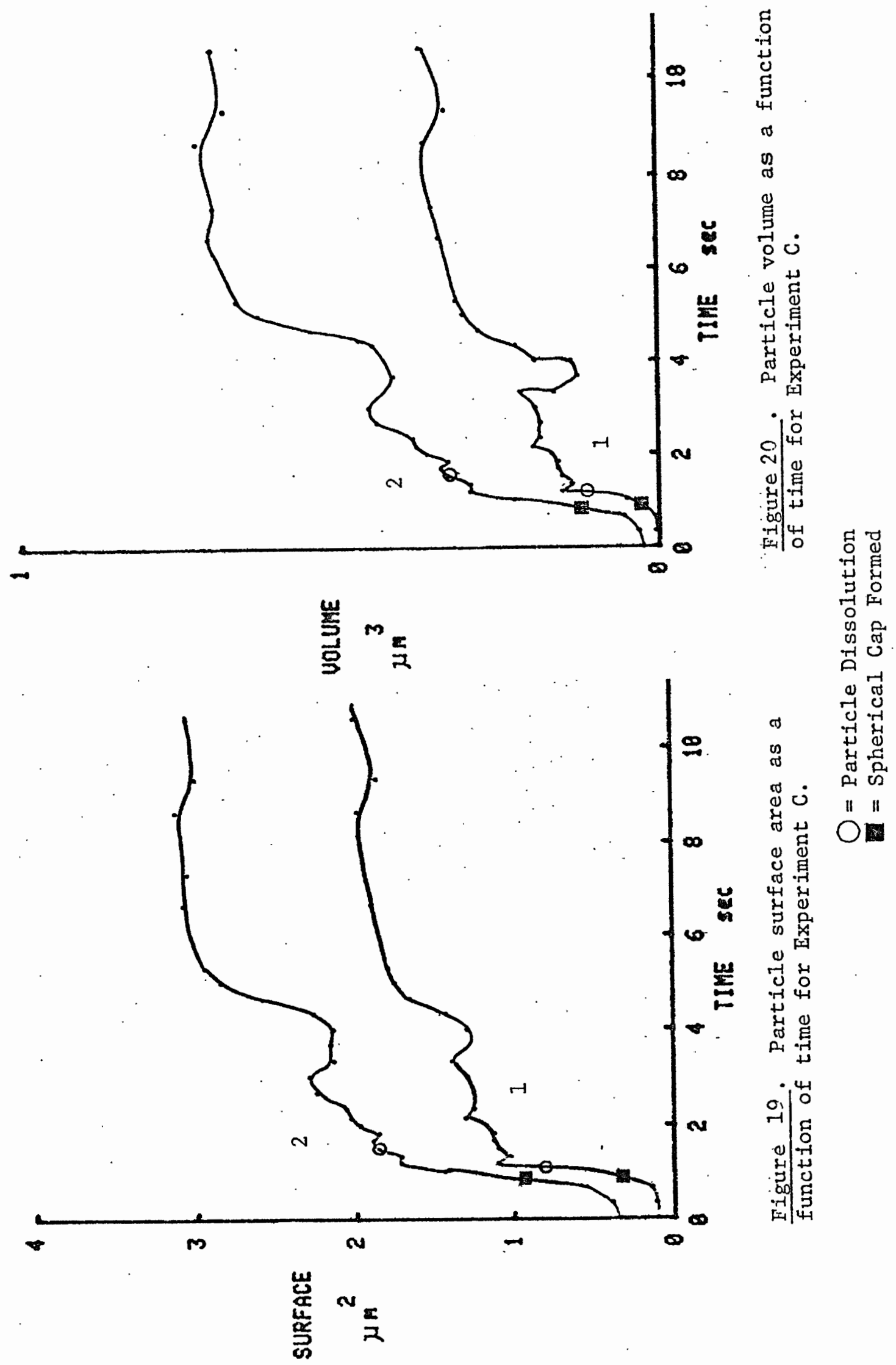




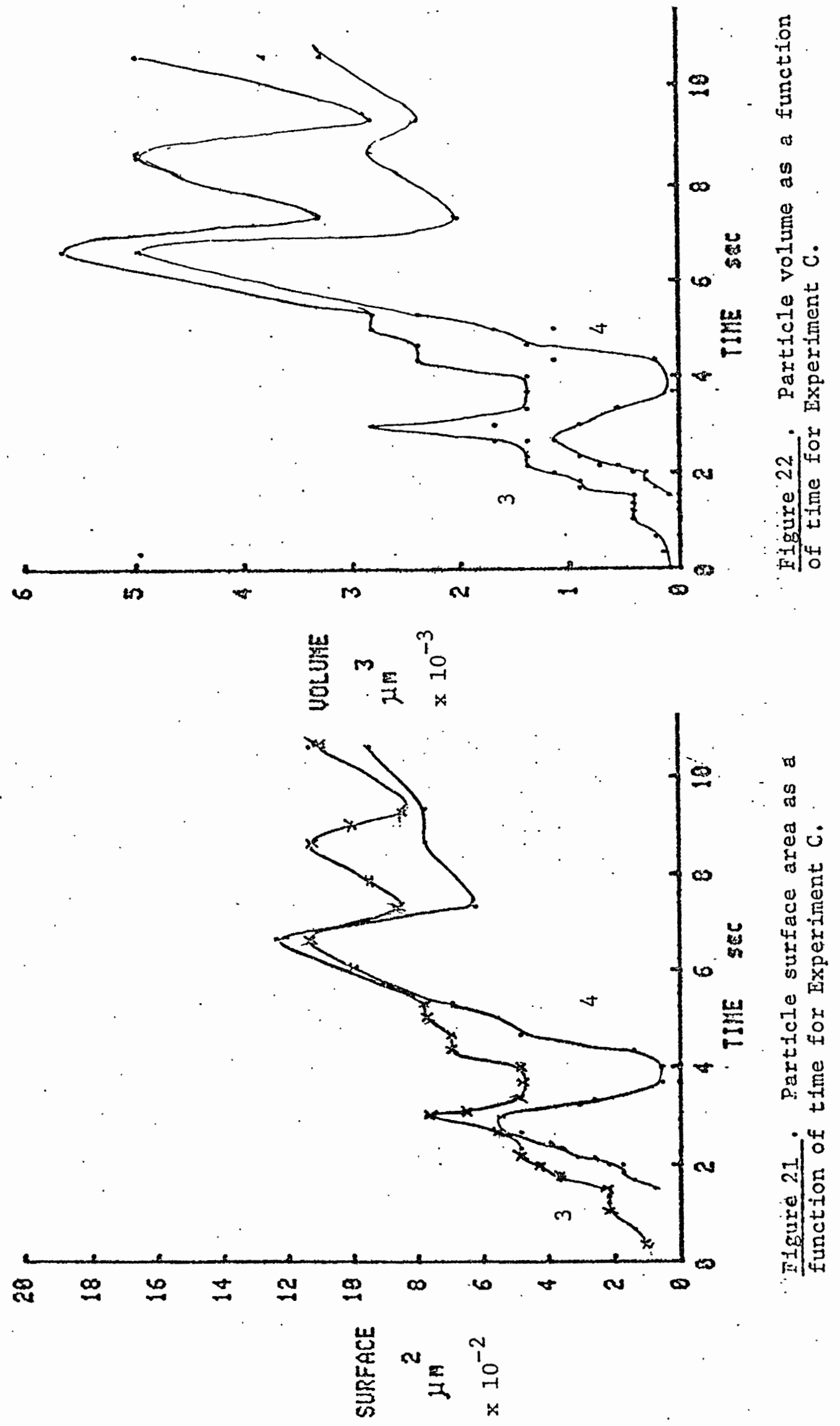


Hydration of the smaller particles observed in experiment $D$ is of interest in that they represent the resolution limitations of this technique in its present form. With a careful eye one can trace the growth of particles from a faint outline of $0.016 \mu$ diameter (particle adjacent to $\mathrm{D}-2$ ) as it grows to a size of $0.04 \mu$ prior to coagulation with others. This size range is of interest in the above mentioned Kelvin and curvature effects. Accurate diameter measurements are Iimited for these sizes; however, as the droplets are thinner than the substrate and contrast, due to absorbtion, is less pronounced. (Substrates for both grids are $\sim 800 \AA$ thick while perceptible droplets are only 200 \& across.) Diameter measurements are correspondingly more difficult to establish with certainty. Approximate growth curves for two of the particles are shown in Figures 24-26. 

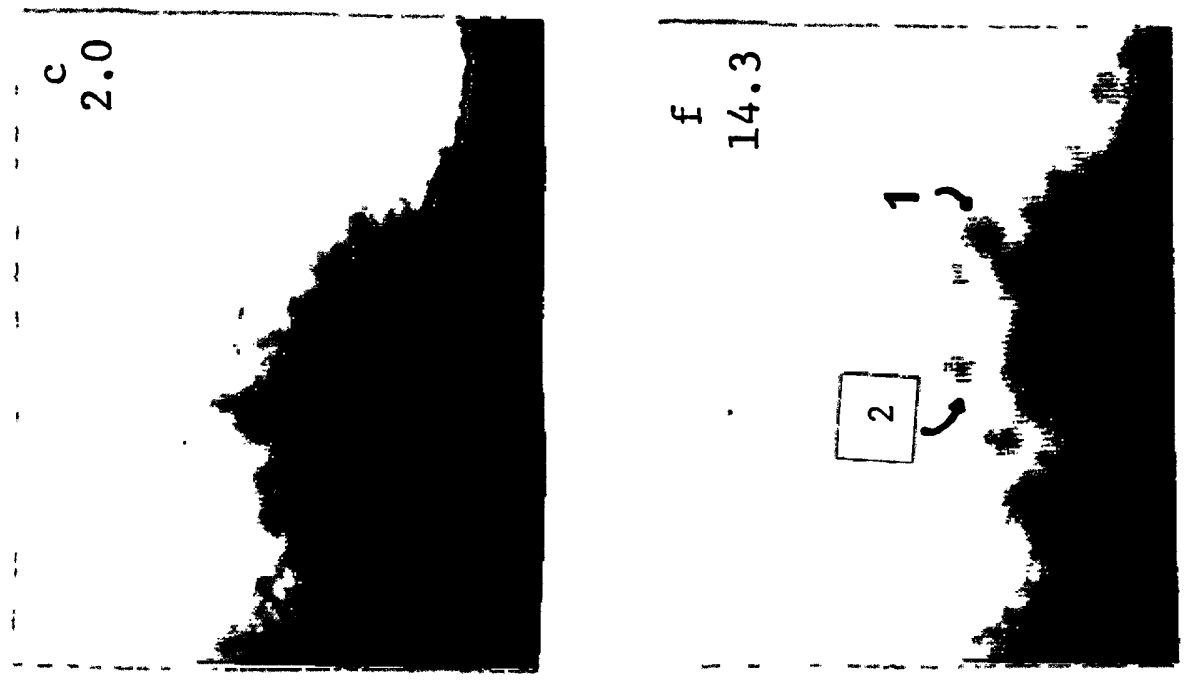

0
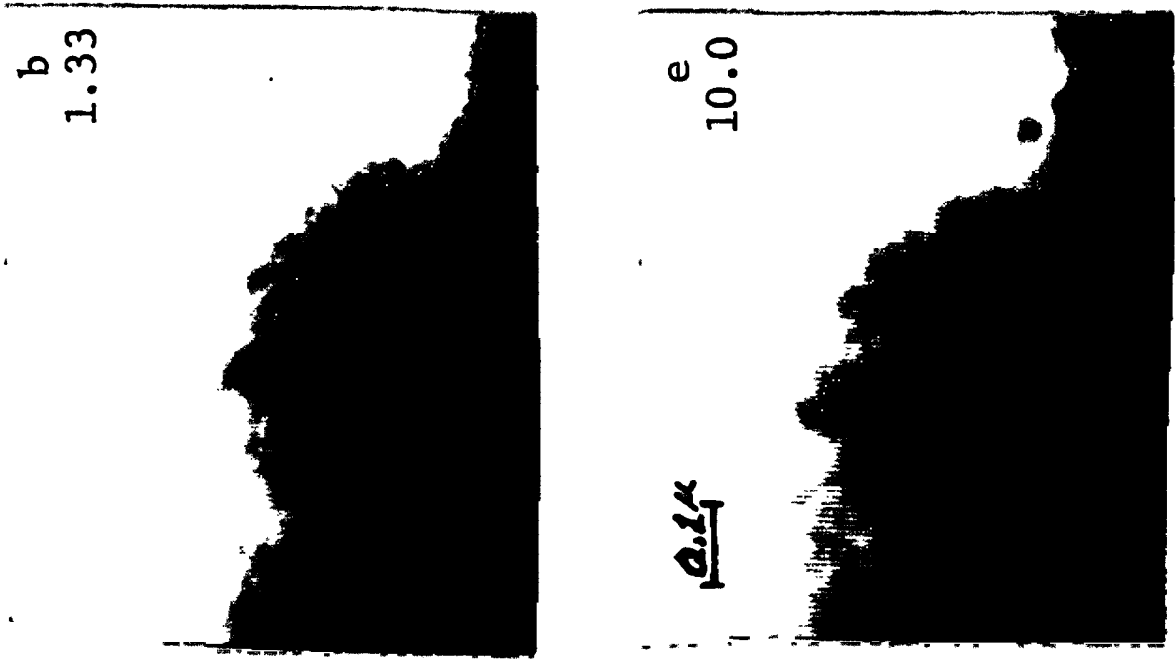

त्
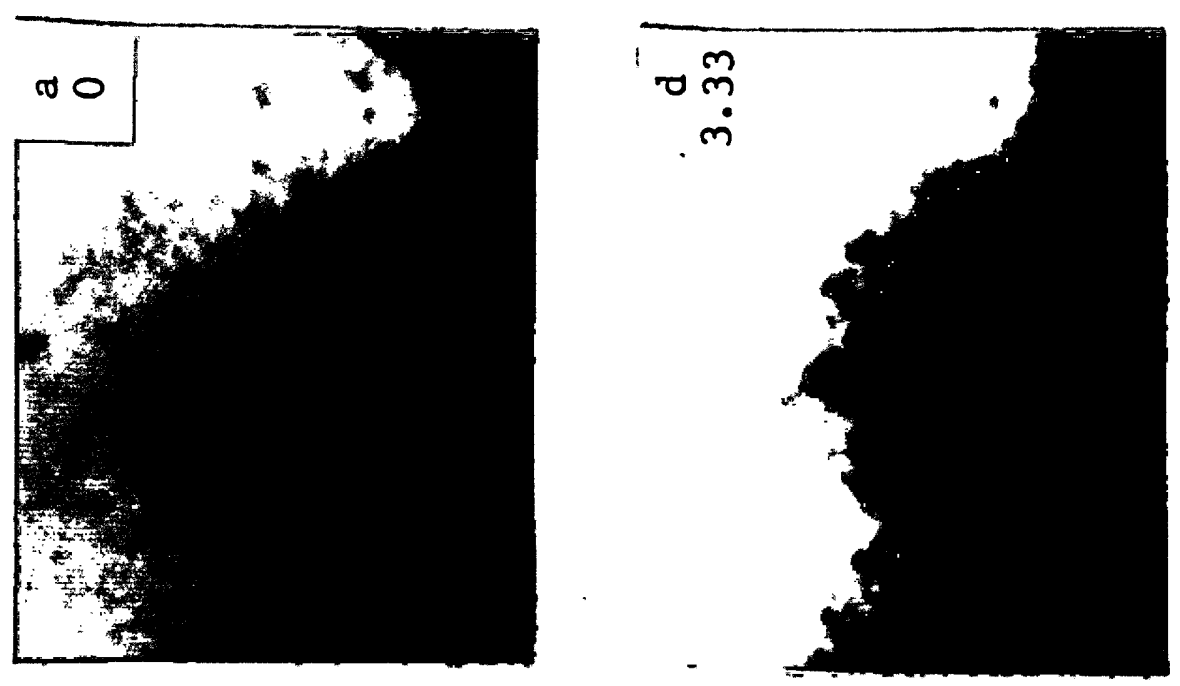

U

$m$
$N$
0
4
5
0
$0-1$
1
1 


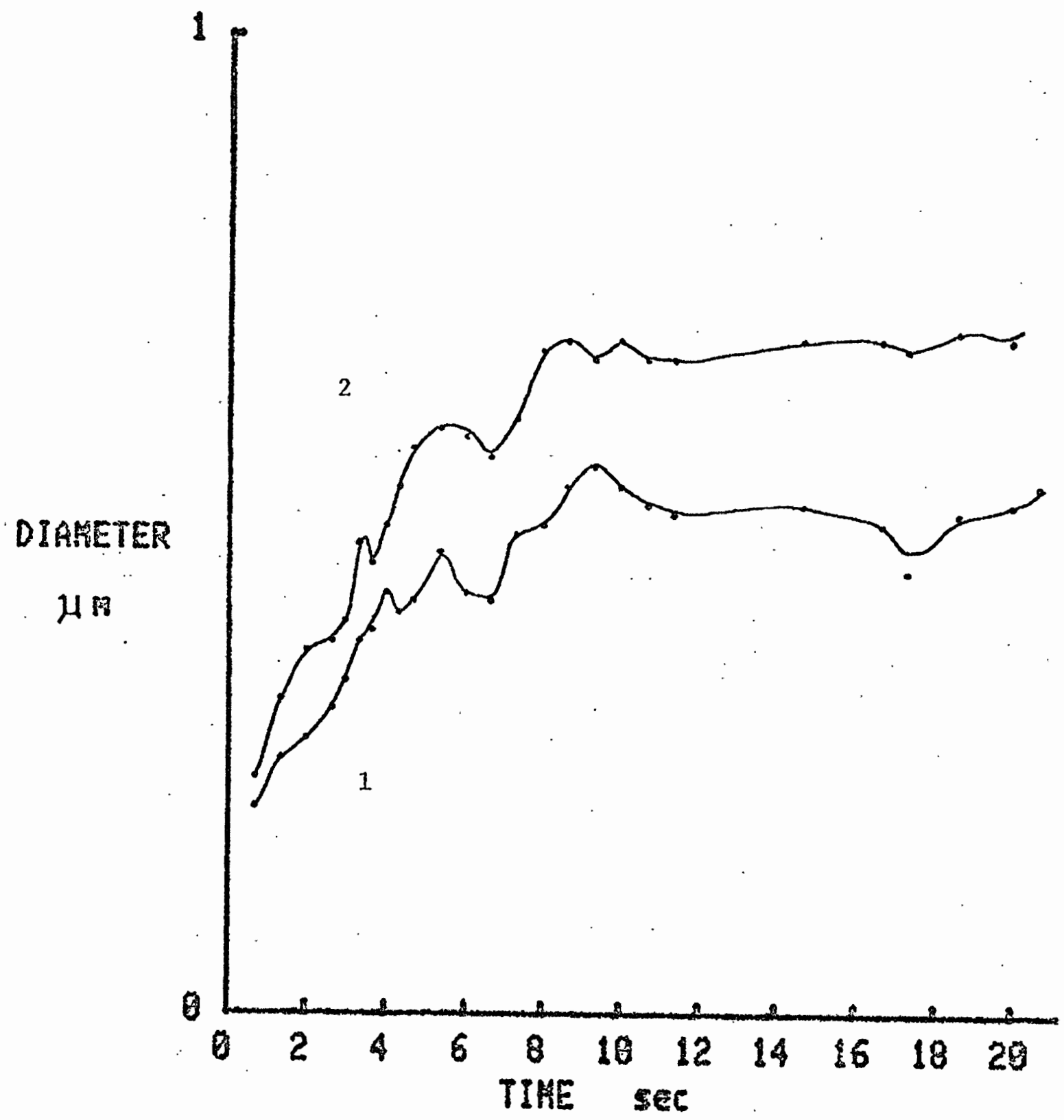

Eigure 24. Paxticle aimeter as a function of time for 

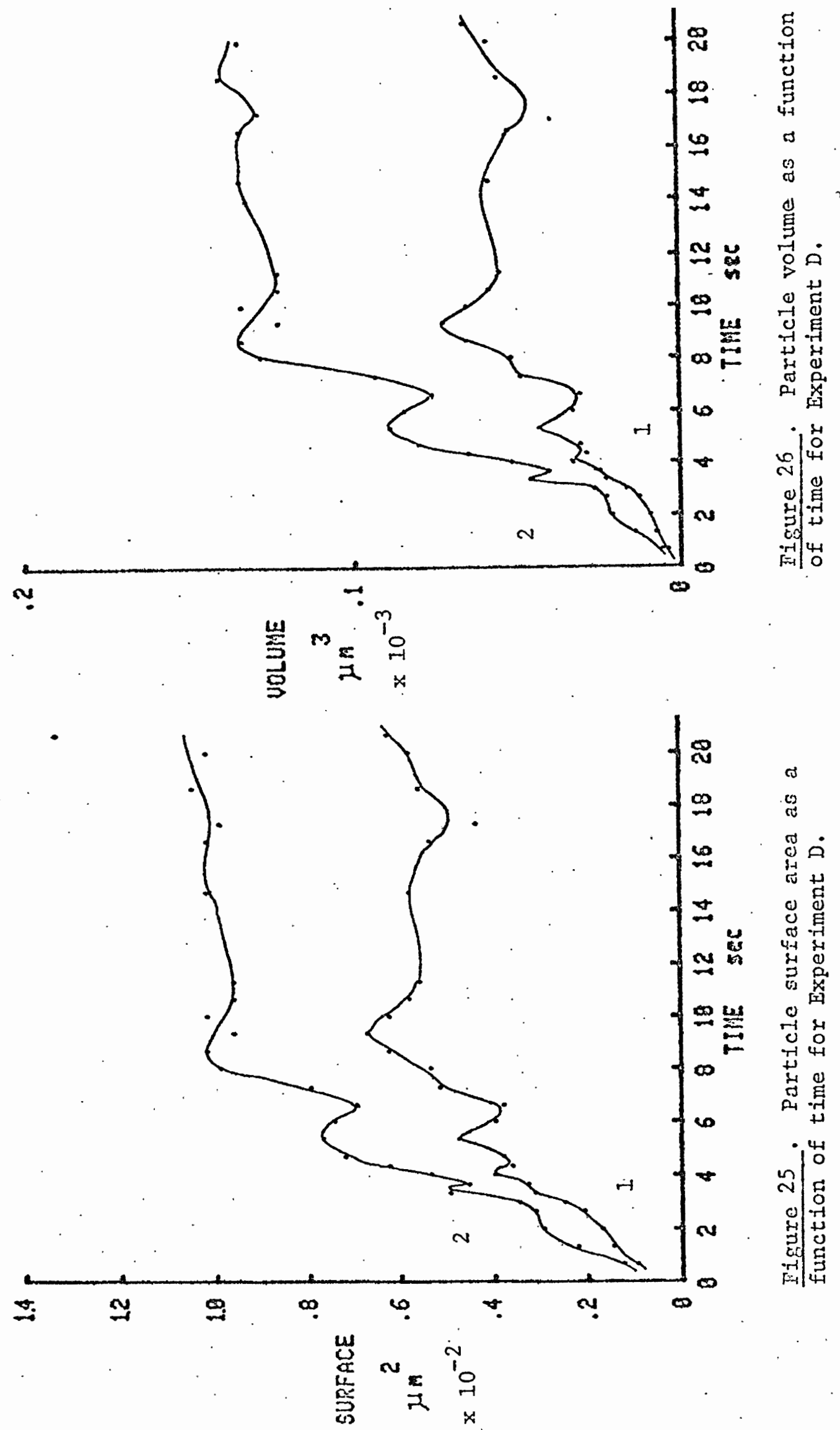


\section{THEORETICAI PRELIMINARY}

In the study of small aerosol particles several effects become apparent that are not observed in the bulk or large droplet phase. Most notable of these is the so-called Kelvin equation, which relates the change in equilibrium vapor. pressure over the surface of a droplet to its radius. An elementary derivation of this equation is presented in Appendix C . The result obtained for equilibrium:

(4) $\quad$ In $\frac{P_{d}}{P_{s}}=\frac{4 \gamma V_{m}}{d_{p} R T}$

$$
\begin{aligned}
& \gamma=\text { solution surface energy } \\
& V_{m}=\text { solution molar volume } \\
& P_{d}=\text { vapor pressure over } d r o p \\
& P_{S}=\text { saturation vapor pressure } \\
& d_{p}=\text { droplet diameter } \\
& T=\text { absolute temperature }
\end{aligned}
$$

Clearly, as the droplet diameter decreases this equation would indicate an increase in equilibrium vapor presșure over the surface of the drop. Calculations for percentage increase in water vapor pressure are about 0.1 percent for $1 \mu \mathrm{m}, 1.1$ percent for $0.1 \mu \mathrm{m}$, and 11 percent for $0.01 \mu \mathrm{m}$ diameter particles (3). (Fig. 27)

When considering the situation for droplets with non-volatile solute one must take into account the vapor pressure lowering of the solute. Over a bulk solution this effect is commonly known as Raoult's Law and can be written as

(5) $P=\operatorname{aXP}_{s}$

$$
\begin{aligned}
& \mathrm{a}=\text { activity coefficient } \\
& \mathrm{X}=\text { mole fraction of solvent } \\
& \mathrm{P}=\text { vapor pressure over solution } \\
& \mathrm{P}_{\mathrm{S}}=\begin{array}{l}
\text { saturation vapor pressure } \\
\text { over solvent }
\end{array}
\end{aligned}
$$


This effect can be combined with the Kelvin equation (see Appendix C ) to yield the following combined expression for equilibrium vapor pressure over the surface of a droplet

(6) $\quad \ln \frac{\mathrm{P}_{d}}{\mathrm{P}_{\mathrm{s}}}=\frac{4 \gamma \bar{V}_{1}}{\mathrm{~d}_{\mathrm{p}} R \mathrm{~T}}-\frac{6 \mathrm{n}_{2} \overline{\mathrm{V}}_{1}}{\pi_{d_{p}}{ }^{3}}$

$$
\begin{aligned}
& \overline{\mathrm{v}}_{1}=\begin{array}{l}
\text { partial molar volume } \\
\text { of solvent }
\end{array} \\
& \mathrm{n}_{2}=\begin{array}{l}
\text { number of moles of } \\
\text { solute }
\end{array}
\end{aligned}
$$

With decreasing droplet diameter the vapor pressure raising of the first term on the right (Kelvin) gives way to the vapor pressure lowering of the second term on the right (solute effect). The combined effect on vapor pressure as a function of radius is revealed in Figure 27.

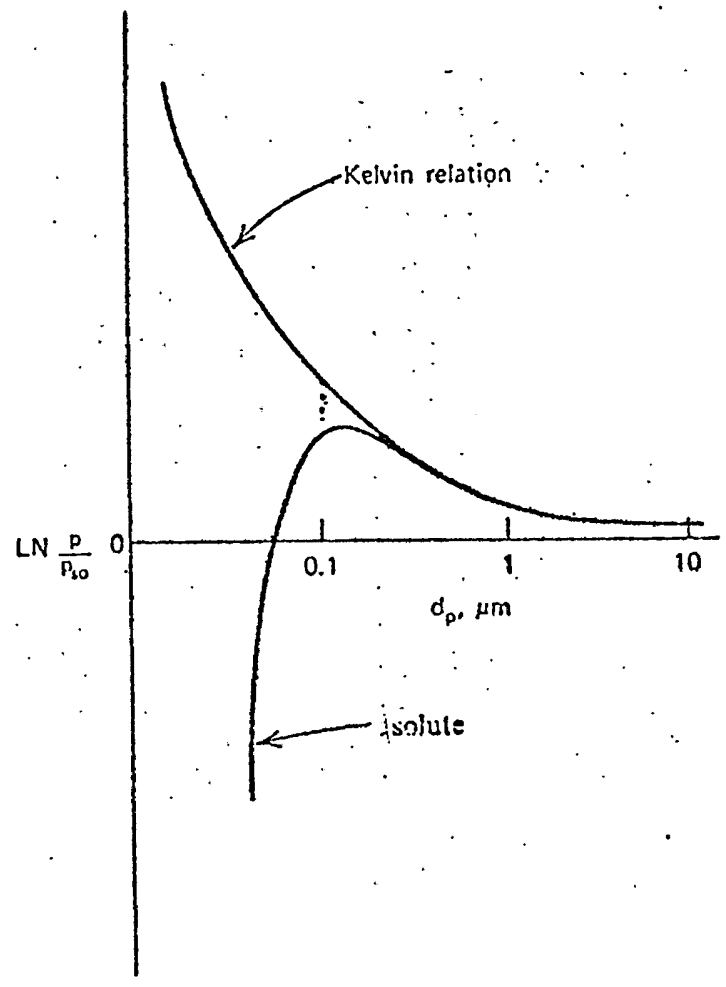

Fig. 27. Equilibrium vapor pressure curves for droplets composed of solvent alone (Kelvin relation) and of a solvent with a fixed mass of non-volatile solute. 
For convenience it is desireable to introduce a form of the above equation (6) used by Fletcher (10):

(7a) $\frac{\mathrm{P}_{\mathrm{d}}}{\mathrm{P}_{\mathrm{s}}}=\left[\exp \left(\frac{4 \gamma \overline{\mathrm{V}}_{1}}{\mathrm{~d}_{\mathrm{p}} \mathrm{RT}}\right)\right]\left[1+\frac{6 \mathrm{n}_{2} \overline{\mathrm{V}}_{1}}{\pi \mathrm{d}_{\mathrm{p}}^{3}}\right]$

This can be simplified for dilute aqueous solutions, to get the following approximation:

(7b) $\frac{\mathrm{P}_{\mathrm{d}}}{\mathrm{P}_{\mathrm{s}}}=1+\frac{4 \gamma \overrightarrow{\mathrm{V}}_{1}}{\mathrm{~d}_{\mathrm{p}} \mathrm{RT}}-\frac{6 \mathrm{n}_{2} \overline{\mathrm{V}}_{1}}{\pi \mathrm{d}_{\mathrm{p}}^{3}}$

Rewriting this in terms of the droplet radius, $r$, and evaluating numerical terms we obtain:

(8)

$$
\begin{aligned}
& \frac{\mathrm{P}_{\mathrm{d}}}{\mathrm{P}_{\mathrm{s}}} \simeq 1+\frac{\mathrm{a}}{\mathrm{r}}-\frac{\mathrm{b}}{\mathrm{r}^{3}} \\
& \mathrm{a} \simeq 3.3 \times 10^{-5} / \mathrm{T} \\
& \mathrm{b} \simeq 4.3 \mathrm{im} / \mathrm{M}
\end{aligned}
$$

$i=v^{\prime} t$ Hoff factor

$\mathrm{m}=$ mass of solute

$\mathrm{M}=$ molecular weight of solute

$\mathrm{T}=$ absolute temperature

A family of such curves for droplets having different amounts of $\mathrm{NaCl}$ can be generated and are commonly known as Kohler curves (Fig. 28 ) (27). These curves indicate that, for a droplet with a given mass of solute, the radius will increase with supersaturation ratio until, at a critical radius, droplet growth continues uninhibited.

Although vapor pressure lowering can be calculated using Raoult's law (dilute solutions), a more accurate method was employed for these studies. This method is based on Raoult's law, but empirical values of water activities are used to calculate vapor pressure lowering at various solute (NaCl) concentrations. Tables of pertinent data are available in Robinson and Stokes (26) for concentrations up to saturation.

Due to considerable uncertainty in pressure and temperature in the immediate environment of the particle, it appeared worthwhile to calculate 


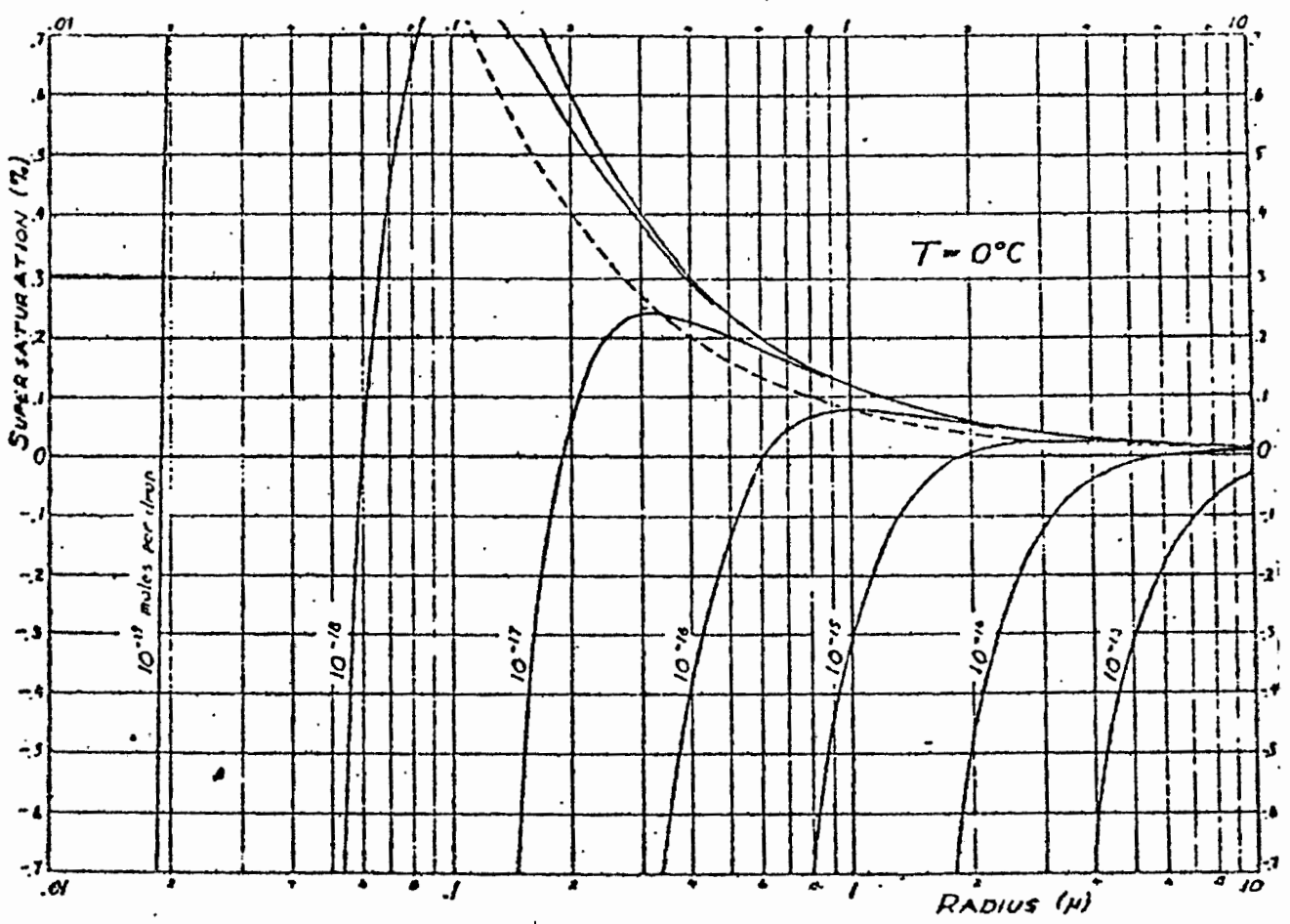

Fig. 28 Equilibrium supersaturation over drops of water containing a given amount of solute. (27)

equilibxium vapor pressures from equilibrlum droplet size estimates and orfginal particle sizes. From this information we can determine the molar and molal concentrations at equilibrium. From the tables mentioned above (26) we can obtain water activities as a function of molality. As the activity of water in solution is by definition the relative humidity $\left(\frac{p}{P_{0}}\right)$, we can thus obtain the equilibrium vapor pressure.

The temperature-dependence of vapor pressure is an essential concern in this experiment. This dependence is shown on the following page (Fig.29). Values for the saturation curve are taken from the Handbook of Chemistry and Physics. The lowered vapor pressure curve is obtained from the saturation curve by using the vapor pressure reduction value (0.753) obtained empixically by Twomey (7) and others. As this reduction value 


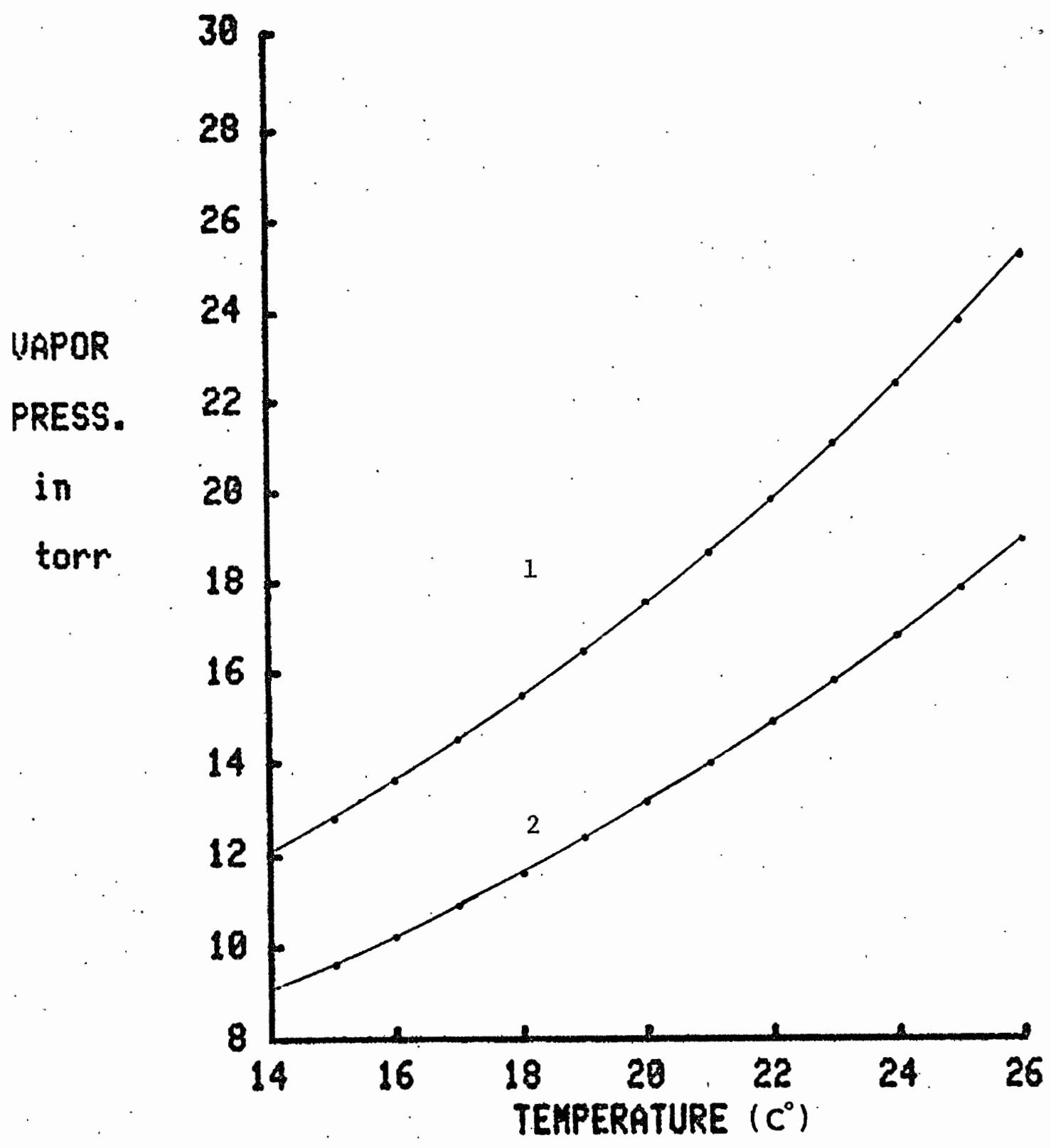

Flgure 29. Plot of equilibrium vapor pressure over pure water (1) and over a saturated solution of $\mathrm{NaCl}$ (2) as a function of temperature. 
is insensitive to temperature in the range of interest in this study, we may have confidence in the graph. Corrections for the effect of temperature on the reduction value, though negligible in this range, can be made using equations presented in Robinson and Stokes (26). The consequences of the above discussion for the hydration of small particles can be summarized as follows:

1. At low relative humidities (R.H.) the particles are covered with a molecular film of $\mathrm{H}_{2} \mathrm{O}$.

2. As R.H. increased particles pick up a little more condensed water that dilutes the liquid film.

3. Some of the salt particle dissolves in the liquid film reducing the particle size and increasing the solution concentration in equilibrium with it.

4. Higher solution concentration lowers equilibrium R.H. over surface and more water vapor condenses.

5. Steps 2-4 repeat and as droplet grows the equilibrium R.H. over the surface is reduced (Kelvin Effect) and more condensation occurs.

6. Above events become unstable and rapid hydration follows until an equilibrium between R.H., droplet size and solution concentration is reached. 


\section{INTERPRETATION OF RESULTS}

As a means of assessing the effect of the beam on the nature of the hydration dynamics, it is desirable to compare quantitative measurements with some theoretical predictions or existing empirical data. This goal was made difficult due primarily to the lack of reliable temperature and pressure measurements in the immediate vicinity of the particles. In spite of careful attention to all elements of the vacuum system, pressure drops exceeded expected values for most experiments, indicating leaks in the system. This rendered flow measurements impossible for the experiments performed.

Temperature measurements, when made, reflected only the mainstream water vapor as it exited the cell. The measured temperature was found to be two to four degrees centrigrade below room temperature. This measurement indicated only that the gas was cooled as it passed through the cell.

Unfortunately, the source of this unexpected behavior was not determined until completion of the series of experiments herein described. The problem was due to the cooling water in the objective lens having been set at $16.5^{\circ} \mathrm{C}$ and left unchanged. This was sufficient to result in a cooling of the stage, sample holder, and ultimately the gas. Due to repeated problems with the pressure and temperature devices, this source of difficulty was the last to be isolated.

Cooling was not significantly reduced until relatively high back pressures (> 12 torr) were used. Above this pressure, the exit gas 
temperature rose one to three degrees centigrade and approached room temperature at over 18 torr. This is a consequence of both an increased flow-rate and a non-linear change in the mean free path $(\lambda)$ as a function of pressure.

A gross estimate of the dependence of $\lambda$ on pressure can be obtained. from kinetic theory using the standard equation (20),

(9) $\lambda=\frac{n}{\rho}\left(\frac{\pi R T}{2 M}\right)^{\frac{2}{2}}$

$$
\begin{aligned}
& n=\text { viscosity of gas } \\
& \rho=\text { density of gas } \\
& M=\text { molecular weight in grams } \\
& R=\text { gas constant } \\
& T=\text { absolute temperature }\left({ }^{\circ}\right)
\end{aligned}
$$

This yields some sample values of $\lambda$ :
$\lambda(1 \operatorname{tor} x)=43 \mu$
$\lambda(5$ tor $x)=8.6 \mu$
$\lambda(15$ torr $)=.2 .9 \mu$
$\lambda(20$ torr $)=2.1 \mu$

Thus, any warming effect of the gas will be substantially greater at higher vapor pressures.

Any estimate of the actual temperature based on theoretical grounds is beyond the scope of this study. Nevertheless, some of the important factors are worth mentioning:

I) The particles are located in the thermal and velocity boundary layers of the gas flow. (Particles therefore must be close to the wall temperature and exposed to low mean gas velocity.)

2) Mean free path varies with pressure. (Rate of gas-particle interactions are pressure dependent.)

3) The well-defined analytical regions are for the free molecule range $\left(\lambda / d_{p}>1\right)$ and the continuum $\left(\lambda_{p} / d_{p}<1\right)$. Many particles 
fall in the transition range for some pressure.

4) Most critical parameters are poorly known experimentally. (Makes analytical evaluation impossible.)

5) Beam heating of particles is uncertain. (Heat transfer to substrate, and gas flow difficult to evaluate.)

The last consideration is of particular significance for the experimental technique. Approximate calculations for a 1 um diameter ionic crystal in a vacuum yields temperature increases in excess of $100^{\circ} \mathrm{C}(28)$. Under high beam intensities and in a vacuum it was possible to evaporate sodium chloride crystals readily. On the other hand, observations made on hydrated droplets in the beam (at.pressures above 75 percent relative humidity), showed less than a 5 percent diameter decrease for a beam current increase of from 3 Ha to 9 Ha (accelerating voltage $100 \mathrm{kV}$ ). However, sustained exposure resulted in the "fading" of droplets at lower pressures, as reported above in experiment $C$. This effect was also observed in the beam on numerous other occasions.

The above-mentioned ccoling problem provides an explanation of the repeated "premature" hydration observed for several of the experiments. At first the spurious phenomena was blamed on the pressure gauge but recalibration after the hydration in experiments $B, C$, and $D$ showed it to be accurate to less than 0.5 torr and values compared favorably with a backup mercury manometer installed later.

Reviewing the pressure record for the hysteresis portion of experiment $B \cdot$ showed each successive hydration (three total during a period of three minutes) to occur at a higher vapor pressure. As we expect 
hydration at 75.3 percent relative humidity (4) and as we have reason to believe our pressure gauge, we can refer to Figure 29 and make an estimate of boundary layer temperature at hydration:

Ist hydration at 10.7 torr (assume $75.3 \% !$ R.H.) $-\mathrm{T} \simeq 16.8^{\circ} \mathrm{C}$ 2nd hydration at 11.4 torr (assume $75.3 \% !$ R.H.) $-\mathrm{T} \simeq 17.7^{\circ} \mathrm{C}$ 3 d hydration at $12.4 \operatorname{torr}$ (assume $75.3 \%, \mathrm{R} . \mathrm{H}$. ) - $\mathrm{T} \simeq 18.6^{\circ} \mathrm{C}$

It is interesting to note that under this assumption initial hydration occurs at $16.8^{\circ} \mathrm{C}$, the temperature of the objective lens. Also the temperature increases with time and pressure as might be expected from the flow rate increase and mean free path decrease with pressure mentioned in the previous section. This temperature change proceeds at $0.7^{\circ} \mathrm{C} /$ minute and compares well with $0.55^{\circ} \mathrm{C} /$ minute cooling rate observed in the cell for a later experiment upon closing the gas inlet.

An estimate of this rate is of value in trying to gain an insight to the hydration of very small droplets observed in experiment C. The pressure at which these particles initiated growth was $\sim 18$ torr after an initial pressure increase of $\sim 12$ torr sustained for $\sim 6$ minutes. If we assume the same temperature change as above for the first three minutes, then we expect the subsequent change to be proportional to the remaining temperature difference (room temperature $=25.6^{\circ} \mathrm{C}$ ). This yields crudely a heating rate of $0.57^{\circ} \mathrm{c} /$ minute for the last three minutes and results in an expected hydration temperature of $\mathrm{T}$ (hydration) $=18.6^{\circ} \mathrm{C}+\left(.57^{\circ} \mathrm{C} /\right.$ min. $)(3$ min. $)=20.3^{\circ} \mathrm{C}$ Referring to Figure 29 it is seen that this corresponds to 13.3 torr at 75 percent R.H. and 18 torr at 100 percent R.H. Hence it would appear that these particles show rapid growth at approximately 
100 percent relative humidity. This coupled with the fact that these appeared as droplets from the moment they were first discernable on the screen suggests they had hydrated previously. The evidence would then indicate that the phenomena being observed is the approach of these droplets to their critical radius as discussed previously and displayed in the Kohler curves above (Fig. 28). Assuming this is the case it is of interest to calculate the expected particle size on the basis of equilibrium droplet diameters and application of equation (9). For the two particles identified in experiment $D$ we get the following values assuming saturation (i.e., $\frac{P_{d}}{P_{s}}=1$ ). Then the Kelvin part of Equation 8 is balanced by the solubility part. Using the droplet diameter for particle No. $2\left(\mathrm{~d}_{\mathrm{p}}=.06 \mu\right)$ we get

$$
\begin{aligned}
& \mathrm{im} / \mathrm{M}=1.2 \times 10^{-19} \\
& \mathrm{~m}=3.5 \times 10^{-18} \mathrm{gm} \\
& \mathrm{V}=\frac{\mathrm{m}}{\rho}=1.62 \times 10^{-18} \mathrm{cc}=1.62 \times 10^{-6} \mu^{3} \\
& \mathrm{~d}=1.2 \times 10^{-2} \ddot{\mu} \\
& \mathrm{d} \simeq 120 \AA
\end{aligned}
$$

For the smaller particle number $1\left(d_{p}=.045\right)$ we get

$$
\begin{aligned}
& \mathrm{im} / \mathrm{M}=.6 .6 \times 10^{-20} \\
& \mathrm{~m}=1.9 \times 10^{-18} \mathrm{gm} \\
& \mathrm{V}=.87 \times 10^{-6} \mathrm{\mu}^{3} \\
& \mathrm{~d}=.9 \times 10^{-3} \mu .
\end{aligned}
$$

Thus the source nuclei for these hydrated droplets were approximately $100 \AA$ in diameter. As this is below the present resolution limit for the cell it accounts for our inability to observe them directly. However, repeated diffraction patterns indicated the presence of small single 
crystals (spot patterns) mixed in with the polycrystalline (ring pattern) residue found on the substrate. This provided confirmation of the existence of particles in this size range.

The origin of these particles still remains an enigma. Although disappearance of hydrated droplets was observed in the beam and the small particles were located in and around their residues, the mechanisms for the processes is obscure. The observations of Twomey and McMaster (29) do show some parallel behavior. They report very large numbers of particles with masses from $10^{-1.4}$ to $10^{-18} \mathrm{gm}$ observed upon the crystalization of large solution droplets $\left(\sim 10^{-10} \mathrm{gm}\right)$. A similar phenomena is observed here for the same sized particles.

Some precautionary remarks are in order with regard to quantitative measurements on the above experiments: Equation (6) above and the more general form eqn. (45) (Appendix C) are derived for spherical particles suspended in a gaseous medium. This differs from the experimental situation of droplets in the shape of spherical caps supported on substrate. It might be hoped to correct these equations by including the volume multiplier (Mv) (Eqn. 27) along with the droplet volume term in these equations. However, in a dynamic situation, the region of negative curvature (i.e. where the droplet meets the substrate Fig. 31) will be the most active condensation site. This may in turn affect both contact angles and growth rates. Furthermore, experiments $B, C$, and $D$ involved a prior hydration and it is possible that residue from prior hydration could affect subsequent contact angles.

Another major source of error is in the estimation of original particle size. As the third dimension is not measured, it must be 
inferred from the other two. If these two dimensions do not reflect cubic symetry additional error is introduced into effective salt diameter $\left(d_{s}\right)$ and size estimates.

Absolute measurements depend on precise knowledge of the net magnification which is accurately known only within \pm ten percent. Fortunately the only place this uncertainty has an effect is in the Kelvin term of Eqn. 45 and when mass determination is needed for use with the Kohler curves. The remaining part of Eqn. 45 and the determination of molar concentrations all involve the ratio of initial and final diameters so that magnification is not concerned and arbitrary units can be used.

It has been shown above and in Appendix $C$ that the effect of curvature on equilibrium vapor pressure is one percent or less for particles above $0.2 \mu \mathrm{m}$ diameter. Consequently, vapor pressure lowering in this range should be little different than the bulk values. Thus, the relative humidity is obtainable from the activities which can be determined from molarities. Molarity calculations require the use of the volume multiplier $\left(M_{v}\right)$ mentioned earlier. Using the value of $M_{v}$ determined in the appendix, the relative humidity at hydration onset is substantially higher than expected.

The volume multiplier is dependent on contact angle. For reasons mentioned above this value may be inaccurate. It is of interest to arrive at another value for it based upon those particles having sizes above $0.2 \mu \mathrm{m}$ and a shape that is most Iikely cubic. Particles $\mathrm{A}_{2}$, $A_{3}$, and $B_{2}$ satisfy these criteria. The new volune multiplier based on these particles can be obtained from activity data and molarity 
calculations outlined previously, yielding the values $0.64,0.60$, and 0.60 respectively. Using the average value $(0.61)$ and the original value 0.78 we can obtain two sets of values for the relative humidity.

$$
\begin{array}{llllllllll}
\text { Particles .... } & \mathrm{A}_{2} & \mathrm{~A}_{3} & \mathrm{~A}_{4} & \mathrm{~B}_{2} & \mathrm{~B}_{3} & \mathrm{~B}_{4} & \mathrm{~B}_{5} & \mathrm{C}_{1} & \mathrm{C}_{2} \\
\text { R.H. }\left(\mathrm{M}_{v}=0.78\right) & .81 & .83 & .87 & .83 & .88 & .88 & .95 & .96 & .87 \\
\text { R.H. }\left(M_{v}=0.61\right) & .75 & .76 & .82 & .76 & .84 & .83 & .94 & .95 & .83
\end{array}
$$

From the above values it is clear that contact angle uncertainty above does not account for the wide range in equilibrium humidities. The greatest difference is for particles $B_{5}$ and $C_{1}$ which are the smaller of each sequence. This points to the uncertainty in original particle measurements as a possible cause. For small particles this is more serious as the television line width places a limit on resolution. As measurements are made in the stop action mode, the video display is made by only one of two scanners used to generate the pictures. As small particles may cover only a few line widths on the screen an original diameter may be uncertain by as much as $15-20$ percent. For the hydrated droplets the uncertainty due to this problem drops to $5-10$ percent.

Supposing a twenty percent greater measurement of $d_{s}$ and $a$ ten percent smaller value of $d_{p}$ for particles $B_{5}$ and $C_{1}$ we obtain a R.H. of 0.84 and 0.87 respectively $\left(M_{V}=0.613\right)$. This brings these values more in line with those calculated for their appropriate experimental group.and indicates a plausible explanation for the scatter in R.H. calculations.

It is important to note that the revised volume multiplier 
$\left(M_{v}=0.61\right.$ ) introduced above should (if valid) be used in equation (34) to establish new dissolution diameters for the particles. The criteria expressed in equation (34) then becomes $1.5 \mathrm{~d}_{\mathrm{s}}<\mathrm{d}_{\mathrm{sc}}<2.65 \mathrm{~d}_{\mathrm{s}}$ for the growth between spherical cap formation and dissolution. This would change the dissolution point indicated on all the previous graphs. In particular, the dissolution point for particles no. 3 and no. 4 in Fig. 14 (hysteresis) would not have been reached. This would support the arguement for hysteresis discussed earlier.

The region of active growth on the previous graphs can also be used to determine growh rates for the particles. By plotting the slope $\left(\frac{\mathrm{dv}}{\mathrm{dt}}\right)$ at a particular time on the volume vs. time graphes against the square of the particle diameter at that time, we get a direct proportion for each experiment. The slope for the relationship differs for each experiment.

As the mean free path in the above experiments is approximately $3 \mu \mathrm{m}$ (p. 44) we are in the transition to the free molecule range for most particle sizes examined. Hence, we expect growth to be characterized by molecular bombardment and governed by the following equation (3):

(10) $\frac{d v}{d t}=\frac{\alpha \pi d_{p}^{2} U_{m}\left(p_{1}-p_{d}\right)}{(2 \pi m k T)^{\frac{1}{2}}}$

$$
\mathrm{p}_{\mathrm{d}}=\begin{aligned}
& \text { equilibrium vapor pressure } \\
& \text { over droplet }
\end{aligned}
$$$$
\mathrm{d}_{\mathrm{p}}=\mathrm{droplet} \text { diameter }
$$$$
U_{\mathrm{m}}=\text { molecular volume }
$$$$
\mathrm{T} \simeq 293^{\circ} \mathrm{K}
$$$$
k=\text { Boltzman's constant }
$$$$
\mathrm{m}=\text { molecular mass }
$$$$
\alpha=\text { accomodation coefficient }
$$$$
p_{1}=\text { actual pressure }
$$ 
This relationship is in accordance with the observations made above and may be solved for $\left(\mathrm{p}_{1}-\mathrm{p}_{\mathrm{d}}\right)$ quantitatively if the accomodation coefficient is taken to be one (i.e. maximum growth rate). The results are listed below for several particles:

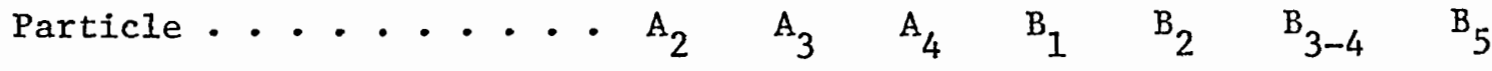

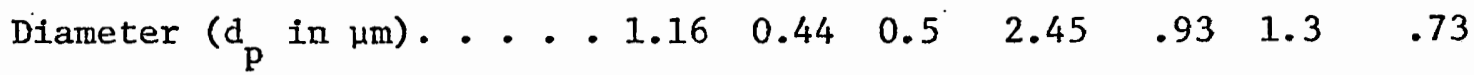

$$
\begin{aligned}
& \begin{array}{llllllll}
\text { Growth Rate }\left(\frac{\mathrm{dv}}{\mathrm{dt}} \text { in } \mu \mathrm{m}^{3} / \mathrm{sec}\right) & 0.315 & 0.035 & 0.043 & 3.8 & .24 & .89 & .16
\end{array}
\end{aligned}
$$

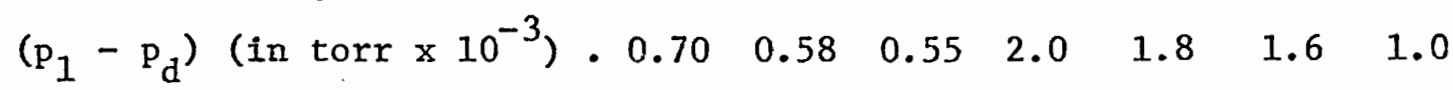

$$
\begin{aligned}
& \text { Particle ................ } \mathrm{B}_{1}^{*} \quad \mathrm{~B}_{3-4}^{*} \quad \mathrm{C}_{1} \quad \mathrm{C}_{2} \quad \mathrm{C}_{1}^{*} \mathrm{C}_{2}^{*} \\
& \text { Diameter }\left(\mathrm{d}_{\mathrm{p}} \text { in } \mu \mathrm{m}\right) . \cdots \cdot \begin{array}{lllllll}
2.2 & 1.7 & .73 & .98 & .81 & 1.1
\end{array}
\end{aligned}
$$

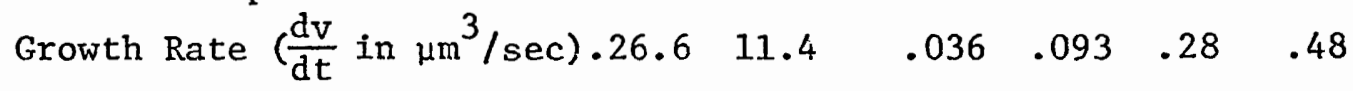

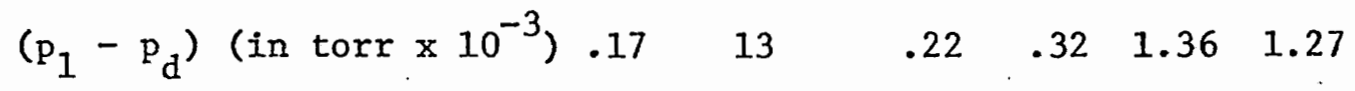

$$
\begin{aligned}
& \text { * indicates second rehydration }
\end{aligned}
$$
a reasonable description of the growth rates observed. It also demonstrates that response to existing vapor pressure fluctuations is very rapid ( $<1 / 30 \mathrm{sec}$ - experimental time resolution) and shows that actual and equilibrium vapor pressure differences are always much less than 0.05 percent of the absolute vapor pressure. Thus, apart from scatter in diameter measurements, the variation in particle size in the preceeding graphs is a measure of local vapor pressure fluctuations on a time scale beyond the resolution of our recording instruments. 


\section{CONCLUSION}

It has been shown that both qualitative and quantitative information obtained from these experiments follow previously established results on the hydration of $\mathrm{NaCl}$. In spite of considerable experimental difficulties, results show that the nature of solid-gas interactions at pressures over 5 torr can proceed without serious beam interaction provided attempts are made to keep beam intensities low and a reasonable gas flow through the chamber. The potential for examining. gas-particle interaction down to diameters of at least $0.02 \mu \mathrm{m}$ looks promising. The type of measurements, time resolution, and the small particle sizes that can be examined, should make this tool particularly advaṇtageous to both aerosol physics and chemistry.

Considerable improvements can and should be made to improve resolution, gas delivery, temperature and pressure measurements. A redesigned chamber to facilitate stereoscopic viewing would be most desirable for providing information on the third dimension. Possibly a new design for support grids would prove advantageous and a mechanism for grid alignment would be a major time saver. Of course, operating the objective lens at near room temperature should be the first step of obtaining more quantitative, predictable, and we11-supported data.

Even so, the results obtained for both the hysteresis (B) and small droplet (C and D) experiments justify the work. With continued improvement the technique should be valuable for providing information on numerous theoretical and practical concerns in relation to small 
particle interactions.

Immediate improvement in quantitative results could be gained by the following proceedures:

1. Introduce latex spheres in the chamber for magnification calibration.

2. Provide shielding between the cold trap $\left(77^{\circ} \mathrm{K}\right)$ and chamber to prevent radlative cocling.

3. Take pictures prior and subsequent to hydration with particular emphasis on small particle sizes.

4. Monitor chamber base temperature and adjust to ambient vapor temperature.

5. Raise pressure rapldiy to critical region but slowly through hydration region using mechanical drive.

6. Mount pressure gauge closer to the cell.

Although additional improvements are possible some problems are inherent to the technique. Growth on a substrate is not equivalent to free particle growth. Consequently, appropriate modification of some of the theoretical development presented in this paper will be necessary. Local temperature measurement for the particle environment in the cell is not experimentally possible and makes extimation of exact hydration pressure only approximate.

Finally, lack of knowledge of particle size in the third dimension makes quantitative size measurements open to substantial uncertainty. In spite of the above objections, there appears to be considerable promise for using the technique to investigate growth rates for gasparticle interactions, sma1l particle formation, hydration effects and related dynamic phenomena. 


\section{SELECTED BIBLIOGRAPHY}

1. Brock J.R. 1971. "Condensational Growth of Atmospheric Aerosols," Aerosols and Atmospheric Chemistry, 1972, Academic Press, Inc.

2. Fuchs, N.A. 1964. "The Mechanics of Aerosols." Pergammon Press.

3. Friedlander, S.K. 1977. "Smoke, Dust and Haze," John Wiley \& Sons.

4. Tang, I.N. and H.R. Munkelwitz and J.A. Davis 1977. "Aeroso1 Growth Studies-II Preparation and Growth Studies of Monodisperse Salt Aerosols," Journal of Aeroso1 Science, 7, 361-371.

5. Orx, Clyde and Kenneth Hurd and Warren P. Hendrix 1958. "The Behavior of Condensation Nuclei under Changing Humidities," Journal of Meterology, 15, 2.40-242.

6. Orr, Clyde and Kenneth Hurd and William Corbett 1958. "Aerosol Size and Relative Humidity," Journal of Colloid Science, 13, 472-483.

7. Twomey, S. 1953. Journal of Applied Physics, 38, 1099.

8. Tang, I.N. and H.R. Munkelwitz and J.A. Davis 1977. "Aerosol Growth Studies-II Preparation and Growth Studies of Monodisperse Salt Aerosols," Journal of Aerosol Science, 8, 149-159.

9. Preinning, O. and D. Sheesley and N. Djordjeuic 1977. "The Size Distribution of Aerosols Produced by Air Blast Nebulization," Journal of Colloidal \& Interface Science, 23-24, 458-461.

10. Fletcher, N.H. 1966. "The Physics of Rain Clouds," Cambridge University Press, 0-390.

11. Cadle, R.D. 1971. "Formation of Chemical Reactions of Atmospheric Particles," 141-147 (ibid.).

12. Goetz, A. and R. Pueschel 1965. Journal of Air Pollution Contr. Ass. $15,90$.

13. Goetz, A. and R. Pueschel 1967. Atmospheric Environment, 1, 287.

14. Chang, Wei and D.F. Parsons 1974. "Use of an Electron Microscope Hydration Chamber," Journal of Microscopy, 102, pt. 2, 219-223.

15. Newton, G.J. and O.G. Raabe and B.V. Mokler 1977. "Cascade Impactor Design and Performance," Journal of Aerosol Science, 8, 339-347. 
16. Knight, Charles A. 1971. "Aerosols as Heterogenous Nuclei," Journal of Colloid Science, 13, 155-159.

17. Winkler, Peter 1973. "The Growth of Atmospheric Aerosol Particles as a Function of the Relative Humidity-II," Aerosol Science, $4,373-387$.

18. Chen, Yu-Tzun 1976. "The Morphology of Aerosols Produced by the Condensation of Sodium Chloride Vapor," A Master's Thesis-University of Missouri-Rolla.

19. Davies, C.N. 1964. "Recent Advances in Aerosol Research," The MacMillan Company.

20. Present, R.D. 1958. "The Kinetic Theory of Gases," McGraw-Hill Book Company, Inc.

21. Adamson, Axthur W. 1976. "The Physical Chemistry of Surfaces," John Wiley \& Sons.

22. Fuchs, N.A. and A.G. Sutugin 1970. "Highly Dispersed Aeroso1s," Ann Arbor Science Publishers.

23. Hidy, G.M. (Editor) 1972. (Aerosols and Atmospheric Chemistry," Academic Press, Inc.

24. Liu, Benjamin Y.H. 1976. "Fine Particles," Academic Press, Inc.

25. Takeo M. 1978. Personal Communication.

26. Robinson, R.A. and R.H. Stokes 1970. Electrolyte Solutions (2nd Rev. Ed.), Butterworths, London.

27. Howe11, Wallace E. 1948. "The Growth of Cloud Drops in Uniformly Cooled Air," Journal of Meteorology, 6, 134-149.

28. Ha11, Cecil E. 1966. "Intróduction to Electron Microscopy," McGraw-Hill,p267

29. Twomey,S. and McMaster,K.N. (1955)"The Production of Condensation Nuclei by Crystallizing Salt Particles," Tellus,7,458 


\section{APPENDIX A}

\section{FLOW CONTROL AND IONIZATION}

Due to the variations in tube diameters leading to the cell, constrictions, impediments (thermocouple wires), and shape factors in the cell geometry, it was decided to determine experimentally flow rates through the cell and any associated pressure drops. To safeguard the microscope the sample holder was removed from the microscope column and suspended in an evacuated chamber. Identical fittings were located at an equal distance $(\sim 5 \mathrm{~cm})$ from the entrance and exit ports of the chamber and an oil manometer connected both $\mathrm{T}^{\prime} \mathrm{s}$ bypass the cell. This enabled any. pressure drop due to flow rate through the cell to be directly observed if it exceeded 0.1 torr. Water vapor was passed through the cell as per experimental conditions and flow was regulated with a WHITEY SSR52-A metering valve. As both forward pressure and valve setting (flow rate) affected pressure drop over the cell, each of these parameters were held constant while the relationship between the remaining two were established.

The results of the above measurements indicated that the flow valve was operating non-linearly over a segment of each turn. It was also determined that a pressure drop greater than 0.5 torr did not take place for valve settings below two full turns with the maximum driving pressure of 20 torr. This pressure drop decreased rapidly to unobservable values for drive pressures less than 10 torr. 
On the basis of the data collected it was decided to operate with a valve setting of $1-20$ ( 1.8 turns). This choice was made in order to maintain the highest possible flow rate without sustaining a significant pressure drop over the cell. A high flow rate is desirable from the standpoint of maintaining an isothermal environment for the sample and to insure that ionization effects due to the beam are held to a minimum.

Using a mercury collection manometer of known volume $(48.5 \mathrm{cc}$ ) and valve setting of 1-20 the manometer pressure as a function of time was recorded while using a driving pressure of 13 torr. This value of drive pressure is close to our region of greatest interest and was accordingly selected for the flow estimates. Although flow rate will vary with drive pressure, our interest is in approximate values only and this will not bother us here.

Observing a generally linear relationship for manometer pressure vs. time, we can obtain an approximate slope.

$$
\begin{array}{rlrl}
\text { slope } & =\mathrm{M}=\frac{\text { change in pressure }}{\text { change in time }}=\frac{\Delta \mathrm{P}_{\mathrm{m}}}{\Delta \mathrm{t}} & \mathrm{P}_{\mathrm{m}}=\text { collection } \\
\mathrm{M} & =0.25 \text { Torr } / \mathrm{min} . & & \text { manometer pressure } \\
M & =0.55 \mathrm{~N} / \mathrm{m}^{2} \mathrm{sec} . &
\end{array}
$$

From the ideal gas equation with $V_{1 n}$ and $T$ held constant

$$
\begin{array}{ll}
\text { (11) } \mathrm{P}_{\mathrm{m}} \mathrm{V}_{\mathrm{m}}=\mathrm{nRT} & \mathrm{V}_{\mathrm{m}}=\text { manometer volume } \\
\text { and differentiating we get: } & \mathrm{R}=8.31 \text { joule/mole } \mathrm{o}_{\mathrm{K}} \\
\text { (12) } \frac{\mathrm{V}_{\mathrm{m}} \mathrm{dP}}{\mathrm{dt}}=\mathrm{RT} \frac{\mathrm{dn}}{\mathrm{dt}} & \mathrm{T}=300_{\mathrm{K}}^{\circ} \\
& \mathrm{n}=\text { number of moles }
\end{array}
$$

or 
(13) $\frac{\mathrm{dn}}{\mathrm{dt}}=\frac{\mathrm{V}_{\mathrm{m}}^{\mathrm{M}}}{\mathrm{RT}}$

where :

(14)

$$
M=\frac{\Delta P m}{\Delta t} \simeq \frac{d P}{d t}
$$

Substituting values we obtain the following estimate: Flow Rate $=\frac{\mathrm{dn}}{\mathrm{dt}}=\frac{\left(0.48 \times 10^{-4} \mathrm{~m}^{3}\right)\left(0.55 \mathrm{~N} / \mathrm{m}^{2} \mathrm{sec}\right)}{(8.31 \text { joule } / \mathrm{mole} \mathrm{OK})\left(300^{\circ} \mathrm{K}\right)} \simeq 10^{-7} \frac{\mathrm{mole}}{\mathrm{sec}}$

Now:

$\mathrm{P}_{\mathrm{o}}=13$ torr $=\frac{13 \text { torr }}{760 \text { torr } / \text { atmosphere }}=0.017$ atmosphere

at 1 atmosphere (STP) I mole of gas occupies 22.41 .

so at 13 torr one mole occupies 1317 1,

or $0.78 \mathrm{moles} / \mathrm{m}^{3}$

And:

Volume of cell $=\pi r^{2} h=3.14\left(\frac{5 \times 10^{-4} \mathrm{~m}}{2}\right)=.1 .9 \times 10^{-10} \mathrm{~m}^{3} / \mathrm{cell}$

Therefore:

$\mathrm{N}=$ 非 of moles in cell at 13 torr $=\left(1.9 \times 10^{-10} \mathrm{~m}^{3}\right) / \mathrm{cel1}$

$N \simeq 1.5 \times 10^{-10}$ mole/cell

Due to chamber design there exists a possibility for leakage

around the cell that is slightly greater than the flow through the cell. Thus the actual flow rate through the cell is about $2 / 5$ the flow rate found above. Hence the flushing rate for the cell is approximately: (15) FLUSH RATE $=\frac{\text { ACTUAL FLOW RATE }}{\text { AMOUNT IN CELL }}=\frac{(2 / 5) \times\left(10^{-7} \mathrm{~mole} / \mathrm{sec}\right)}{1.5 \times 10^{-10} \mathrm{~mole} / \mathrm{ce} 11}$ FLUSH RATE $\simeq 250 \frac{\text { FLUSHES }}{\mathrm{sec}}$ (at drive pressure of 13 torr) 
With this flush rate through a cell approximately $5 \times 10^{-4} \mathrm{~m}$ across we arrive at a mean gas velocity on the order of $0.10 \mathrm{~m} / \mathrm{sec}$. That yields a Reynolds number of $\sim 25$ and indicates that laminar flow is to be expected.

The above information combined with some calculations on ionization of the water vapor in the beam allows a computation of ion density in the cell at any instant.

$$
\text { (16) } \begin{aligned}
\text { \# molecules in cell } & =N_{0} \times \text { (\$moles in cell) } N_{0}=\underset{\text { Avogadro's }}{\text { Aumber }} \\
& =\left(6.02 \times \frac{10^{23}}{\text { mole }}\left(1.5 \times 10^{-10} \frac{\text { mole })}{c e 11}\right.\right. \\
& \simeq 9.0 \times 10^{13} \text { molecules } / \text { cell }
\end{aligned}
$$

With a maximum beam current density of $\sim 10^{4} \mathrm{ma} / \mathrm{m}^{2}$ on the sample. and a beam diameter of $40 \mu \mathrm{m}$ (Area $\simeq 5 \times 10^{-10} \mathrm{~m}^{2}$ ) we obtain $\sim 3 \times 10^{10}$ electrons/sec. passing through the cell. A calculation from Dr. Takeo ( 25.) arrives at 0.1 ionization per incident electron for water vapor at 10 torr. This results in $3 \times 10^{9}$ ionization/sec. in the cell. If the cell is flushed at 250 FLUSHES/sec. then the ions present at any instant are $\sim 10^{7}$ compared to $\sim 10^{14}$ molecules. Under these conditions we expect charging not to be a problem. However, at low pressures and low flow rates it can have a substantial effect.

Other potential effects due to ionization are also unlikely to be a problem in this experiment. As the reduction in vapor pressure over charged nuclei depends on the inverse fourth power of the radius (3) the effect becomes negligible for particle diameters over $50 \AA$ and need not concern us. Furthermore, any condensation on ions that might occur would have to take place at substantial supersaturations (10) not encountered in these experiments. Consequently, we expect the effects of charging 
or ionization to have no significant observable effects under typical experimental conditions. 
APPENDIX B

\section{CONTACT ANGLE}

To evaluate volume or mass growth rates for the droplets or water envelopes, it was essential to know the shape of the droplet as it sat on the microscope grid. This required a knowledge of the contact angle on the grid surface (Formvar). As this information was not located in the literature, experimental measurements were made using a modified sessile drop method mentioned in Adamson (21).

This approach involved viewing horizontally an illuminated droplet placed on the sample grid with a fine capillary syringe. Measurements were made using a travelling scale incorporated into the eyepiece of the microscope. Due to Iarge differences between the advancing and receding contact angles coupled with rapid droplet evaporation under illumination, measurements had to be made immediately after depositing the droplet. This approach best represented the advancing contact angle.present in the experimental droplet growth situation.

As height change was more rapid than base change under evaporation (Fig. 30 ), it was measured first and the base measurement followed. These dimensions were more efficiently made than the usual radius and allowed the angle to be calculated according to the following relationship: 

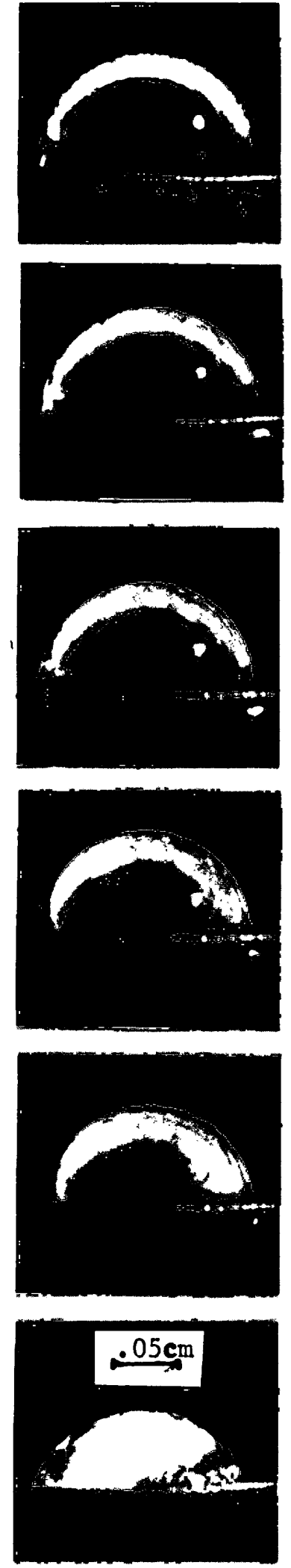

b.

$15 \mathrm{sec}$.

a.

$0.0 \mathrm{sec}$

c.

$30 \mathrm{sec}$.

d.

$45 \mathrm{sec}$.

e.

$60 \mathrm{sec}$. f.

(150 ses.

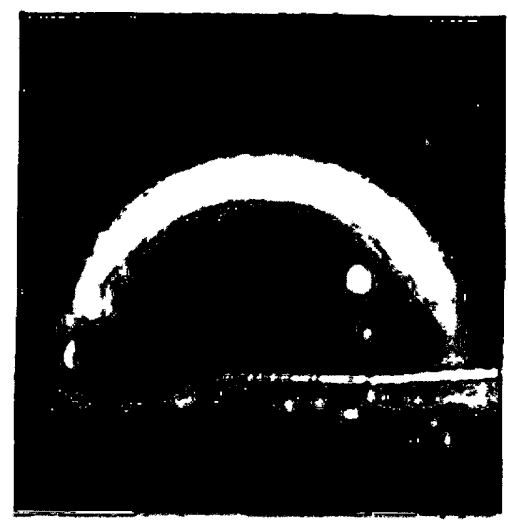

$a^{\prime}$

(enlargement of a.)

Figure 30 . Typical view of a droplet on the electron microscope grid as seen during contact angle measurements. Time sequence shows evaporation and corresponding change in contact angle under illumination. Note the thin edges of droplet at low contact angles that would result in transparency to the electron beam for small droplets. 
Referring to Fig. 31 and assuming a spherical envelope:

$$
\begin{aligned}
& h=r+1 \\
& b / 2=r \cos \phi \\
& 1=r \sin \phi \\
& \theta=90^{\circ}+\phi
\end{aligned}
$$

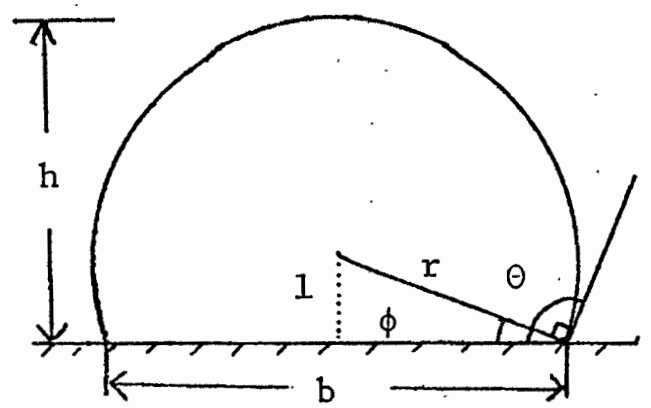

Fig. 31 Measurements used for the evaluation of the contact angle $(\theta)$.

(18) $\sin \phi=1 / \mathrm{r}=\frac{\mathrm{h}-\mathrm{r}}{\mathrm{r}}=\frac{\mathrm{h}}{\mathrm{r}}-1=\frac{2 \mathrm{~h} \cos \phi}{\mathrm{b}}-1$

$$
\begin{aligned}
& \sin ^{2} \phi=\frac{4 h^{2}}{b^{2}} \cos ^{2} \phi-\frac{4 h}{b} \cos \phi+1 \\
& \cos ^{2} \phi=\frac{4 h^{2}}{b^{2}} \cos ^{2} \phi+\frac{4 h}{b} \cos \phi \text { or } \cos \phi=\frac{4 h}{b}-1+\frac{4 h^{2}}{b^{2}}
\end{aligned}
$$

Therefore:

(19) $\theta=90^{\circ}+\cos ^{-1}\left[\frac{4 \mathrm{hb}}{4 \mathrm{~h}^{2}+\mathrm{b}^{2}}\right]$

In view of the complete or near complete saturation of the droplet under initial growth conditions the above measurements were done for both pure distilled water and a saturated solution. The results yielded a value of $\Theta_{A D V}=110^{\circ}$ for pure distilled water and a value of $\theta_{A D V}$ $\simeq 114^{\circ}$ for a saturated solution. A sampling of ten measurements for each yielded a standard deviation of $\sim 2$ degrees. 
To see if these observations are reasonable we can compare them to observations found in Adamson ( 21 ). By extrapolating his graph on surface energy vs. concentration for the $\mathrm{NaCl}-\mathrm{H}_{2} \mathrm{O}$ system we get a free energy for pure water of $73 \frac{\text { dyne }}{\mathrm{cm}}$ and for saturated $83 \frac{\text { dyne }}{\mathrm{cm}}$. The following relationship for contact angle as a function of surface energy is provided by the same author:

(20) $\gamma_{L V} \cos \theta=\gamma_{S V}{ }^{\circ}-\gamma_{S L}$

$$
\begin{aligned}
\gamma_{L V}= & \text { surface free energy of } \\
& \text { liquid-vapor interface. } \\
\gamma_{\mathrm{SV}}= & \text { surface free energy of } \\
& \text { surface-vapor interface } \\
& \text { at saturated vapor } \\
& \text { pressure. } \\
\gamma_{\mathrm{SL}}= & \text { surface free energy of } \\
& \text { surface-liquid interface. }
\end{aligned}
$$

During saturation $\gamma_{\mathrm{SV}^{\mathrm{O}}}$ will not change and if we further note that $\gamma_{\mathrm{SL}}$ is approximately $3 \mathrm{erg} / \mathrm{cm}^{2}$ (21) then we say that:

(21) $\cos \theta \simeq \frac{K}{\gamma_{L V}} \cdot \quad K=$. constant

and

$$
\text { (22) } \frac{(\cos \theta) \text { SATURATED }}{(\cos \theta) \text { PURE }}=\frac{\left(\gamma_{\text {LV }}\right) \text { PURE }}{\left(\gamma_{\text {LV }}\right) \text { SATURATED }}
$$

Assuming a value of $110^{\circ}$ for pure water we get:

$$
\begin{aligned}
& (\cos \theta) \text { SATURATED }=\frac{73.0}{82.0} \cos 110^{\circ}=.300 \\
& \Theta \text { SATURATED }=112.5^{\circ}
\end{aligned}
$$

Therefore:

$$
\Theta \text { SATURATED }-\theta \text { PURE } \simeq 2.5^{\circ}
$$


Considering experimental uncertainty this value compares favorably with observed results for contact angle measurements.

The droplet solution changes from saturation concentrations of $\mathrm{NaCl}$ to often less than half saturation upon reaching equilibrium. As the contact angle is relatively insensitive to such changes, an approximate value of $112^{\circ}$ was assumed to hold during the experiment. The error introduced in such an assumption is substantially less than other sources insofar as this experiment is concerned.

With the above value for contact angle we can evaluate corresponding droplet volumes and areas.

Referring to Figure 32 we get the following expression for an element of surface area.

$$
\begin{array}{rlrl}
\mathrm{dS} & =(2 \pi r \cos \phi)(\mathrm{rd} \phi) & \mathrm{S}=\text { surface of spherical cap } \\
\mathrm{dS} & =2 \pi r^{2} \mathrm{~d}(\sin \phi) & & \mathrm{S}_{\mathrm{o}}=\begin{array}{c}
\text { surface } \\
\text { radius }
\end{array} \\
\mathrm{S} & =2 \pi r^{2} \int_{-\frac{\pi}{2}}^{\theta-\pi / 2} \mathrm{~d} \sin \phi & & \theta=\operatorname{contact} \text { angle }=112^{\circ} \\
\mathrm{S} & =2 \pi \mathrm{r}^{2}[\sin (\theta-\pi / 2)+1] & \\
\mathrm{S} & =4 \pi r^{2}\left(\frac{-\cos \theta+1}{2}\right) & & \\
\mathrm{S} & =0.68 \mathrm{~S}_{0}
\end{array}
$$

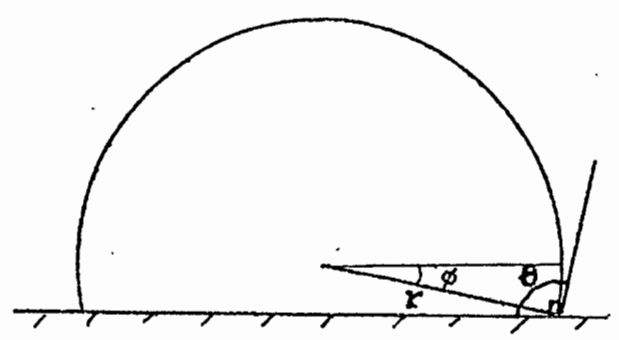

Figure 32. Spherical Cap 
Similarly we can describe an element of volume:

(25)

$$
\begin{aligned}
& d V=\pi r^{2} \cos ^{2} \phi d(r \sin \phi) \quad V=\text { volume of spherical cap } \\
& d V=\pi r^{3} \cos ^{3} \phi d \phi \\
& -V=\pi r^{3} \begin{array}{rr}
\theta-\pi / 2 \\
\cos ^{3} \phi d \phi
\end{array} \\
& -\pi / 2 \\
& V=\frac{\pi r^{3}}{3}\left[\sin \phi\left(\cos ^{2} \phi+2\right)\right]_{-\pi / 2}^{\theta-\pi / 2} \\
& V=\frac{4}{3} \pi r^{3}\left[\sin (\theta-\pi / 2)\left[\frac{\cos ^{2}(\theta-\pi / 2)}{4}+\frac{1}{2}\right]+1 / 2\right] \\
& \mathrm{V}=0.78 \mathrm{~V} \\
& \mathrm{~V}_{\mathrm{o}}=\underset{\text { volume of }}{\text { radius }} \text { sphere of equal }
\end{aligned}
$$

Thus we can define multipliers to obtain actual surface and volumes in terms of spheres having the observed diameters:

(26) $M_{S}=\frac{S}{S_{0}}=0.68$ surface multiplier

(27). $M_{v}=\frac{V}{V_{0}}=0.78$ volume multiplier

Precaution must be taken in the application of the above multipliers to particles that have not yet formed a spherical envelope. The same is true for evaporating droplets, for which the contact angle will be much different from the growing droplets (Figure 30).

For the first case one does not expect growth to be symmetric until an envelope exists of sufficient size to enclose the crystal. A lower limit for this to happen can be estimated for cubic crystals by referring to the contact angle measurements. Using an approximate geometrical construction we can obtain a relationship between a cube and the size of a spherical cap (sc) needed to enclose it. This is illus- 
trated in the following Figure 33. Note that the corners of the cube have been rounded in accord with experimental observations.

From direct measurements we get:

(28) $\mathrm{d}_{\mathrm{sc}}=1.5 \mathrm{~d}_{\mathrm{s}}$

where:

$d_{s c}=$ diameter of spherical cap

$d_{S}=$ diameter of salt particle

$\mathrm{V}_{\mathrm{sc}}=$ volume of spherical cap

$\mathrm{V}_{\mathrm{S}}=$ volume of salt particle

In terms of volume this yields:

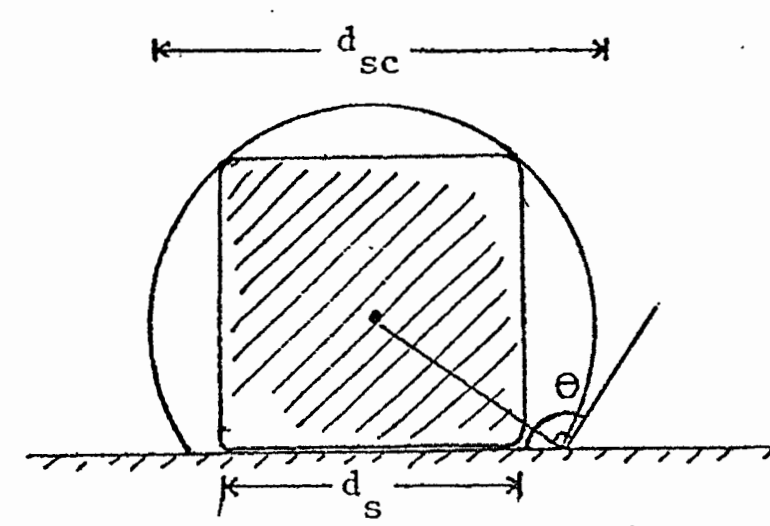

Figure 33. Salt Crystal and its Spherical Cap.

$v_{s c}=M_{v \frac{\pi}{6}}\left(d_{s c}\right)^{3}$

(29) $\mathrm{v}_{\mathrm{sc}}=(.78) \frac{\pi}{6}\left(\mathrm{~d}_{\mathrm{sc}}\right)^{3} \simeq 1.4 \mathrm{~V}_{\mathrm{s}}$

Hence the volume of the envelope $\left(v_{e}\right)$

(30) $\mathrm{V}_{\mathrm{e}}=\mathrm{V}_{\mathrm{sc}}-\mathrm{V}_{\mathrm{s}}=0.4 \mathrm{~V}_{\mathrm{s}}$

As the only salt particle diameter we have measurements on are prior to hydration, we should estimate the partial dissolution of $\mathrm{NaCl}$ in the envelope.

As saturation requires $0.36 \mathrm{gm} \mathrm{NaC1}$ we get:

$0.36 \frac{g m}{c c} V_{e}=V_{c d} \rho_{s} \quad v_{c d}=$ volume of NaCl dissolved

$0.36 \mathrm{v}_{\mathrm{e}}=\mathrm{v}_{\mathrm{cd}}(2.165) \quad \mathrm{v}_{\mathrm{e}}=$ volume of the envelope only

(31)

$$
\mathrm{v}_{\mathrm{cd}}=0.17 \mathrm{~V}_{\mathrm{e}} \quad \rho_{\mathrm{s}}=\text { density of } \mathrm{NaCl}
$$


Therefore, the original salt particle had a volume $\left(V_{s o}\right)$ such that (32)

$$
\mathrm{V}_{\mathrm{so}}=\mathrm{V}_{\mathrm{cd}}+\mathrm{V}_{\mathrm{s}}=0.17 \mathrm{~V}_{\mathrm{e}}+\mathrm{V}_{\mathrm{s}}=(0.17)(0.4) \mathrm{V}_{\mathrm{s}}+\mathrm{V}_{\mathrm{s}}=1.07 \mathrm{~V}_{\mathrm{s}}
$$

Thus there is only a $7 \%$ 'change in the salt volume or approximately a $2 \%$ change in diameter due to dissolution in the just-formed spherical cap. As this is less than the uncertainty in diameter measurements, it will not be considered here. For our purposes, the criteria for the formation of a complete envelope will be that mentioned above (i.e. $\left.\mathrm{d}_{\mathrm{sc}}=1.5 \mathrm{~d}_{\mathrm{s}}\right)$. Points at which this should occur are indicated on the appropriate graphs with a solid square.

In a calculation similar to above one can determine the point at which the particle can be expected to dissolve completely into the water envelope.

At saturation we have from above the condition for dissolution:

$$
\mathrm{V}_{\mathrm{sc}}(0.36 \mathrm{gm} / \mathrm{cc})=\mathrm{V}_{\mathrm{s}}(2.165 \mathrm{gm} / \mathrm{cc})
$$

$$
\mathrm{V}_{\mathrm{Sc}}=6.01 \mathrm{~V}_{\mathrm{s}}
$$

or in terms of the diameters:

$$
(0.78) \frac{\pi}{6}\left(\mathrm{~d}_{\mathrm{sc}}\right)^{3}(0.36 \mathrm{gm} / \mathrm{cc})=\left(\mathrm{d}_{\mathrm{s}}\right)^{3} 2.165 \mathrm{gm} / \mathrm{cc}
$$

$$
\mathrm{d}_{\mathrm{sc}}=2.45 \mathrm{~d}_{\mathrm{s}} \text { (for cubic particles) }
$$

Thus, for a cubic particle undergoing hydration, it is expected to dissolve into a growing spherical cap of water (at saturation) when the following condition is satisfied:

$$
1.5 \mathrm{~d}_{\mathrm{s}}<\mathrm{d}_{\mathrm{sc}}<2.45 \mathrm{~d}_{\mathrm{s}}
$$

This region is indicated on the appropriate graphs as that portion included between the solid square and the open circle. 
APPENDIX C

A. Elementary Derivation of Kelvin Equation.

Consider two spherical surfaces as illustrated:

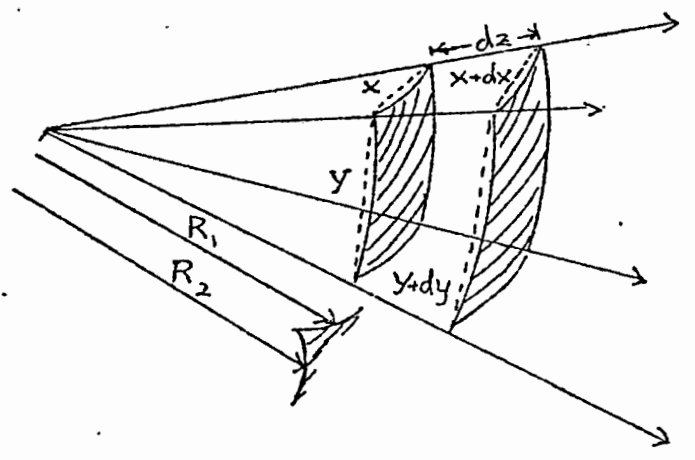

Pressure difference over

Surface $=. \Delta P$

Area Change $=\Delta \mathrm{A}=(\mathrm{x}+\mathrm{dx})$

$(y+d y)-x y$

Figure 34. Diagram for Kelvin Equation.

$\Delta A=x d y+y d x$

Work to create surface $=W=(\Delta \mathrm{P}) \mathrm{Ad} z=(\Delta \mathrm{P}) \mathrm{xyd} z$

From Thermodynamics we can write:

Molecular free energy $=\Delta G=j \mathrm{vdp}$ for $\mathrm{T}=$ Constant and

$$
\mathrm{V}=\text { Molar Volume }
$$

From the concept of surface tension the work required to generate new surface is given by the surface tension times the change in area. $W_{S}=\gamma 1 d x=\gamma d A$ where $\gamma$ can be interpreted as surface tension per unit length or as a surface energy per unit area.

Referring to the illustration we have from similar triangles:

$\frac{\mathrm{x}+\mathrm{dx}}{\mathrm{R}_{1}+\mathrm{dz}}=\frac{\mathrm{x}}{\mathrm{R}_{1}} \quad$ and $\quad \frac{\mathrm{y}+\mathrm{dy}}{\mathrm{R}_{2}+\mathrm{dz}}=\frac{\mathrm{y}}{\mathrm{R}_{2}}$

or

$\mathrm{dx}=\frac{\mathrm{xdz}}{\mathrm{R}_{1}}$ and $\mathrm{dy}=\frac{\mathrm{ydz}}{\mathrm{R}_{2}}$ 
As $W=W s$ we can write:

(37) $\Delta \mathrm{P}=\frac{\gamma \mathrm{dA}}{\mathrm{xydz}}=\gamma\left(\frac{1}{\mathrm{R}_{1}}+\frac{1}{\mathrm{R}_{2}}\right)$

Hence we obtain the following form known as Young's Equation:

(38) $\Delta \mathrm{G}=\mathrm{V} \Delta \mathrm{P}=\gamma \mathrm{V}\left(\frac{1}{\mathrm{R}_{1}}+\frac{1}{\mathrm{R}_{2}}\right)$

From the ideal gas Iaw (Eqn. 11) where $V$ is now the molar volume, we get upon differentiation (at constant $\mathrm{T}$ ):

(39) $\mathrm{pdV}+\mathrm{Vdp}=0$

As $\Delta G=-\int p d V$ and substituting $d V=-\frac{R T}{p^{2}} d p$ (from the ideal gas 1aw)

we obtain:

(40) $\Delta \mathrm{G}=\mathrm{RT} \ln \frac{\mathrm{P}}{\mathrm{P}_{0}}$

Therefore

$$
\ln \frac{P}{P_{0}}=\frac{\Delta G}{R T}=\frac{2 \gamma V}{R T}\left(\frac{1}{R_{1}}\right) \text { where } R_{1}=R_{2} \text { for a sphere }
$$

This is the well known Kelvin Equation. It can be rewritten for convenience in the following form:

(41) $\ln \frac{\mathrm{P}_{\mathrm{d}}}{\mathrm{P}_{\mathrm{s}}}=\frac{4 \gamma_{\mathrm{m}}^{\mathrm{V}}}{\mathrm{d}_{\mathrm{p}} \mathrm{RT}}$

$$
\begin{aligned}
& \gamma=\text { surface energy } \\
& v_{\mathrm{m}}=\text { molar volume } \\
& \mathrm{P}_{\mathrm{d}}=\text { vapor pressure over drop } \\
& \mathrm{P}_{\mathrm{s}}=\text { saturation vapor pressure } \\
& \mathrm{d}_{\mathrm{p}}=\text { droplet diameter }
\end{aligned}
$$


This equation is presented in a paper by orr (6) and expresses the equilibrium droplet activity as a function of particle diameter and bulk solution activity as follows:

(47) In $\left(\frac{A_{d}}{A_{b}}\right)=\frac{4 \gamma M}{\rho R T} \cdot\left(\frac{1}{d_{p}}\right)$

for NaCl we get:

$$
\operatorname{In}\left(\frac{A_{d}}{A_{b}}\right)=3.6 \times 10^{-7} \mathrm{~cm}\left(\frac{1}{d_{p}}\right)
$$

which yields some typical values:

$$
\begin{aligned}
& \frac{A_{d}}{A_{b}}=1.0036 \text { for } d_{p}=1 \mu \\
& \frac{A_{d}}{A_{b}}=1.036 \text { for } d_{p}=.1 \mu \\
& \frac{A_{d}}{A_{b}}=1.36 \text { for } d_{p}=.01 \mu
\end{aligned}
$$

As the activity ratio is equivalent to the vapor pressure lowering above the droplet, it is clear that smaller particles will tend to hydrate at lower relative humidities than larger particles. However, as indicated above, this effect will not be significant until particle diameters are less than $0.1 \mu \mathrm{m}$. 
B. Effect on non-volatile solute. (Friedlander [3])

From Raoult's Law we obtain the expression for vapor pressure reduction over a surface

(42) $P=\alpha X P S$

$\alpha=$ activity coefficient

$X=$ mole fraction of solvent

Droplet volume can be written

$$
\begin{aligned}
& \frac{\pi \mathrm{d}^{3}}{6}=\mathrm{n}_{1} \overline{\mathrm{v}}_{1}+\mathrm{n}_{2} \overline{\mathrm{V}}_{2} \quad \mathrm{n}_{1} \& \mathrm{n}_{2} \text { moles } / 1 \text { solvent and solute } \\
& \overline{\mathrm{v}}_{1} \& \overline{\mathrm{V}}_{2} \begin{array}{l}
\text { partial molar volume of solvent } \\
\text { and solute respectively }
\end{array}
\end{aligned}
$$

This can be rewritten in terms of mole fractions

$$
\frac{1}{x_{1}}=1+\frac{\dot{n}_{2} \bar{V}_{2}}{n_{1} \bar{V}_{1}}=1+\frac{n_{2} \bar{V}_{1}}{\frac{\pi d}{6}{ }^{3}-n_{2} \bar{V}_{2}}
$$

Combining the above with the Kelvin Equation yields

$$
\ln \frac{\mathrm{Pd}}{\mathrm{Ps}_{0}}=\frac{4 \gamma \bar{\nabla}_{1}}{\mathrm{~d}_{\mathrm{p}} \mathrm{RT}}+\ln \alpha_{1}-\ln \left[1+\frac{\mathrm{n}_{2} \overline{\mathrm{V}}_{1}}{\pi \mathrm{d}_{\mathrm{p}}^{3} / /^{-n_{2}} \overline{\mathrm{V}}_{2}}\right]
$$

For dilute droplets with $\alpha_{1}=1$ and $n_{2} \bar{v}_{2} \ll \pi d_{p}^{3} / 6$ we get

(46) $\ln \frac{P d}{P_{0}}=\frac{4 \gamma \bar{V}_{1}}{d_{p} R T}-\frac{6 n_{2} \bar{V}_{1}}{\pi d_{p}^{3}}$

The first term on the right reveals the Kelvin effect while the second refers to vapor pressure lowering. of the solute. This equation reveals that for small droplets solute effects are dominant and opposed to curvature (Kelvin Eqn.) effects that take place at increased radius. With further increase of radius both effects become negligible. The above equation does not include the effect of small solute particle diameters on the equilibrium solution concentration in the envelope. 


\section{APPENDIX D}

PARTICLE DIAMETER MEASUREMENTS

\section{TABLE I}

PARTICLE DIAMETERS FOR EXPERIMENT A MEASURED AGAINST TIME

\begin{tabular}{|c|c|c|c|c|}
\hline & & & & p2 \\
\hline $\begin{array}{l}1.66 \\
2 \\
2.33 \\
2.66 \\
3 \\
3.33 \\
3.66 \\
4 \\
4.33 \\
4.66 \\
5 \\
5.16 \\
5.33 \\
5.5 \\
5.66 \\
5.83\end{array}$ & $\begin{array}{l}1.88 \mu \\
1.13 \\
1.17 \\
1.2 \\
1.24 \\
1.31 \\
1.35 \\
1.44 \\
1.55 \\
1.6 \\
1.69 \\
1.73 \\
1.76 \\
1.79 \\
1.82 \\
1.87 \\
1.92 \\
1.97 \\
2.15\end{array}$ & $\begin{array}{l}0.32 \mu \\
8.33 \\
0.37 \\
0.38 \\
0.41 \\
0.45 \\
0.5 \\
0.57 \\
0.61 \\
8.66 \\
8.69 \\
0 \\
8.7 \\
8.7 \\
8.7 \\
8.7 \\
8.7 \\
8.7 \\
0.7\end{array}$ & $\begin{array}{l}8 \\
8 \\
8.31 \\
8.31 \\
B .32 \\
0.35 \\
8.39 \\
0.44 \\
8.46 \\
\theta .5 \\
8.57 \\
0.57 \\
8.62 \\
8.62 \\
8.64 \\
\theta .65 \\
8.66 \\
0.66 \\
8.66 \\
0.66\end{array}$ & $\begin{array}{l}8.61 \mu \\
8.65 \\
8.68 \\
8.73 \\
8.79 \\
0.84 \\
8.92 \\
0.98 \\
1.88 \\
1.16 \\
1.21 \\
1.29 \\
1.32 \\
1.36 \\
8\end{array}$ \\
\hline
\end{tabular}


$x$

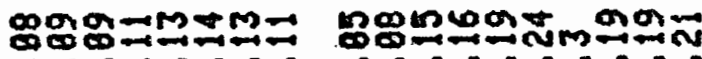

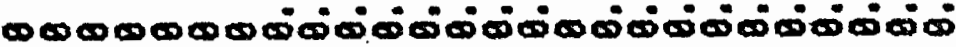

2

器星

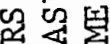

四画

怘

폰

点

덜 空

군

돈

睰

A.

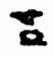

3

$\aleph$

$\ddot{a}$ $\underbrace{0}_{\substack{0 \\ 0}}$

工

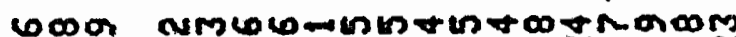

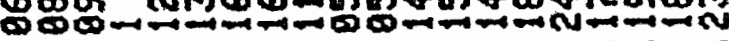

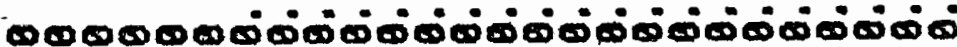

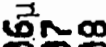

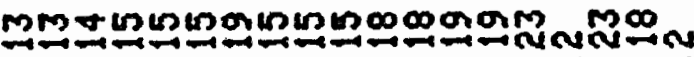

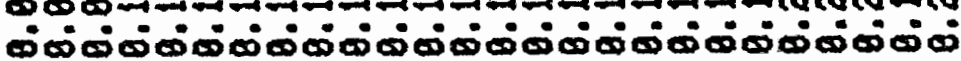

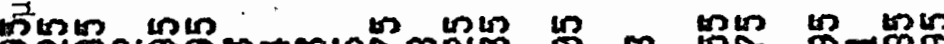

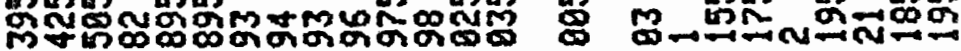

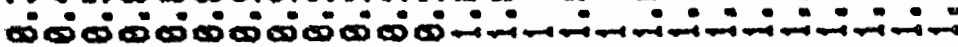

군

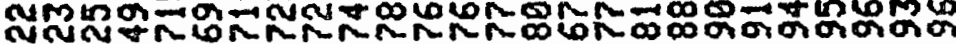

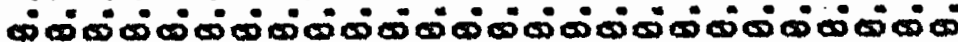

Me LM

M品 $\infty 0^{\circ}-1-1$ -

2

$\$$

똥요

co

क्व

空星

$\stackrel{H}{H}$

됟

崬

mif-1

点䀡

돈

要是

要

出

m

紧

$\ddot{a}$
10

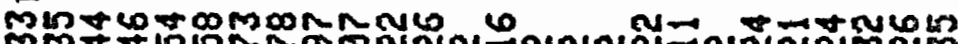

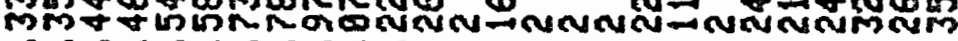

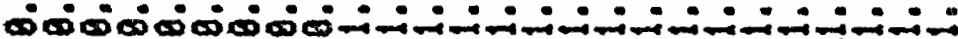

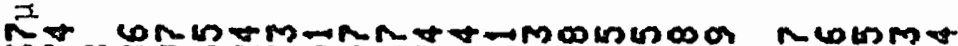
6ั

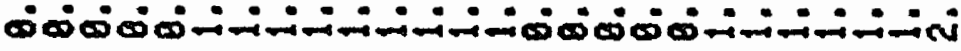

궁

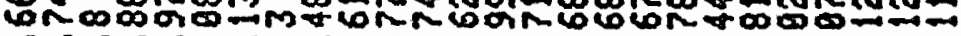

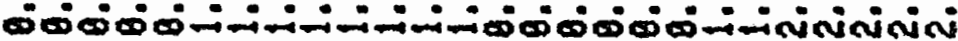

2

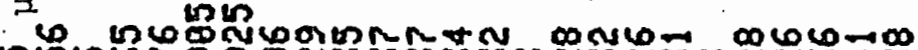

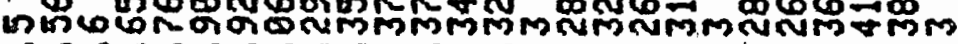

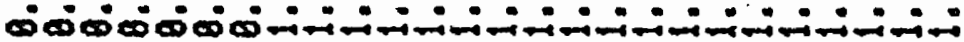

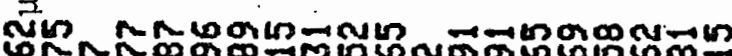

ONR

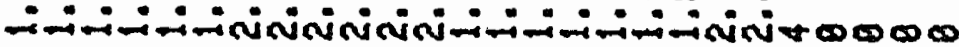

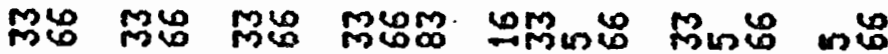

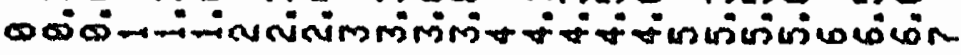


PARTICLE DIAMETER MEASUREMENTS

\section{TABLE IV}

PARTICLE DIAMETERS FOR EXPERIMENT D

. MEASURED AGAINST . TIME

\begin{tabular}{|c|c|c|}
\hline $\begin{array}{l}\text { tine } \\
\text { sec }\end{array}$ & & $\frac{p 2}{10_{\mu}^{-1}}$ \\
\hline $\begin{array}{l}0.66 \\
1.33 \\
2 \\
2.66 \\
3 \\
3.33 \\
3.66 \\
4 \\
4.33 \\
4.66 \\
5.33 \\
6 \\
6.66 \\
7.33 \\
8 \\
8.66 \\
9.33 \\
18 \\
10.66 \\
11.33 \\
14.66 \\
16.66 \\
17.33 \\
18.66 \\
29 \\
20.66\end{array}$ & $\begin{array}{l}0.21 \\
0.26 \\
0.28 \\
0.31 \\
0.34 \\
0.38 \\
0.39 \\
0.43 \\
0.41 \\
0.42 \\
0.47 \\
0.43 \\
0.42 \\
0.49 \\
0.5 \\
0.54 \\
0.56 \\
0.54 \\
0.52 \\
0.51 \\
0.52 \\
0.55 \\
0.45 \\
0.51 \\
0.52 \\
0.54\end{array}$ & $\begin{array}{l}0.24 \\
8.32 \\
8.37 \\
0.38 \\
8.4 \\
8.48 \\
0.46 \\
8.5 \\
8.54 \\
8.58 \\
8.6 \\
8.59 \\
0.57 \\
0.61 \\
0.68 \\
8.69 \\
0.67 \\
0.69 \\
0.67 \\
0.67 \\
0.69 \\
8.69 \\
8.68 \\
8.7 \\
0.69 \\
0.79\end{array}$ \\
\hline
\end{tabular}

